\title{
Neuroimaging of Children Following Prenatal Drug Exposure
}

\author{
Chris Derauf $^{a, 1}$, Minal Kekatpure ${ }^{b, 1}$, Nurunisa Neyzi ${ }^{b, 1}$, Barry Lester ${ }^{c}$, and Barry \\ Kosofskyb,2 \\ aJohn A. Burns School of Medicine, University of Hawaii, Honolulu, HI \\ ${ }^{b}$ Department of Pediatrics, New York Presbyterian Hospital, Weill Medical College of Cornell University, \\ New York, NY \\ ${ }^{\mathrm{c} B r o w n}$ Center for the Study of Children at Risk, Warren Alpert Medical School of Brown University and \\ Women and Infants' Hospital, Providence, RI
}

\begin{abstract}
Recent advances in MR-based brain imaging methods have provided unprecedented capabilities to visualize the brain. Application of these methods has allowed identification of brain structures and patterns of functional activation altered in offspring of mothers who used licit (e.g., alcohol and tobacco) and illicit (e.g., cocaine, methamphetamine, and marijuana) drugs during pregnancy. Here we review that literature, which though somewhat limited by the complexities of separating the specific effects of each drug from other confounding variables, points to sets of interconnected brain structures as being altered following prenatal exposure to drugs of abuse. In particular, dopaminerich cortical (e.g., frontal cortex) and subcortical (e.g., basal ganglia) fetal brain structures show evidence of vulnerability to intrauterine drug exposure suggesting that during brain development drugs of abuse share a specific profile of developmental neurotoxicity. Such brain malformations may shed light on mechanisms underlying prenatal drug-induced brain injury, may serve as biomarkers of significant intrauterine drug exposure, and may additionally be predictors of subsequent neuro-developmental compromise. Wider clinical use of these research-based non-invasive methods will allow for improved diagnosis and allocation of therapeutic resources for affected infants, children, and young adults.
\end{abstract}

\section{Keywords}

Prenatal Drug Exposure; Neuroimaging; MRI; Drugs of Abuse; Behavioral Teratology

\section{INTRODUCTION}

Recent advances in the field of magnetic resonance (MR) based neuroimaging have greatly improved our understanding of alterations in brain structure, function and metabolism resulting from prenatal exposure to licit and illicit drugs of abuse. This in turn has aided researchers in identifying potential hypotheses explaining brain-behavior relationships underlying the

\footnotetext{
2Corresponding author. Barry Kosofsky, MD, PhD, Chief, Division of Child Neurology, Weill-Cornell Medical College, New York Presbyterian Hospital, 525 East 68th Street, Box 91, New York, NY 10021 (USA), Tel. +1 212746 5942, Fax +1 212746 8137, E-Mail E-mail: bar2009@med.cornell.edu.

${ }^{1}$ Contributed equally to this manuscript

Publisher's Disclaimer: This is a PDF file of an unedited manuscript that has been accepted for publication. As a service to our customers we are providing this early version of the manuscript. The manuscript will undergo copyediting, typesetting, and review of the resulting proof before it is published in its final citable form. Please note that during the production process errors may be discovered which could affect the content, and all legal disclaimers that apply to the journal pertain.
} 
prenatal drug-exposed phenotype, and has also conferred unique opportunities to examine in detail the structural, metabolic and functional consequences of prenatal drug exposure in vivo. One of the great advantages of these neuroimaging methods is that they are safe and noninvasive, which enables repeated studies in single individuals including infants and children, making them ideal tools for monitoring longitudinal brain development in this population.

These neuroimaging techniques utilize differences in tissue density to produce data that can be reconstructed into visual images, which can then be analyzed quantitatively using specialized software packages and data processing pipelines. By standardizing the acquisition of such MR data sets across magnets of different field strength manufactured by different vendors, these results can then be compared across different groups of patients, and across multiple sites and studies. Unfortunately, due to the extensive cost and time required to conduct such studies and analyze the resulting data, sample sizes often tend to be small, increasing chances for bias, thus underlying a need for replicating the results of any individual study in any particular cohort.

MRI (magnetic resonance imaging) is the most commonly used research-based brain imaging modality as it provides accurate neuroanatomical details regarding brain structure, which can additionally be used to quantitate the volume of specific brain areas when advanced methods enabling brain morphometry are applied. Such morphometric methods may be manual, semiautomated or fully automated into a data analysis pipeline (e.g., FreeSurfer). Alternative MRbased neuroimaging methods include functional MRI (fMRI) and MR Spectroscopy (MRS), which can provide information regarding functional and metabolic aspects of particular brain regions of interest, respectively. Diffusion Tensor Imaging (DTI) is becoming an increasingly used imaging modality to study white matter structure and integrity. ADC (Apparent Diffusion Coefficient) and the FA (Fractional Anisotropy) are two important variables derived from DTI data sets, which show region-specific patterns accompanying normal brain maturation, and specific patterns of variation underlying particular brain pathologies, thus providing important information of changes occurring within the white matter of the brain. To date the application of MRS has been primarily limited to proton spectroscopy, which can resolve only a handful of molecules of sufficient abundance in the brain (e.g., choline, and $\mathrm{N}$-acetylaspartate, constituents of white matter and grey matter, respectively) to be identified using standard clinical scanners with field strengths of 1.5 and 3 Tesla (T).

MR technology is evolving at a rapid pace, fostering the use of higher field strength magnets that will improve the resolution of additional compounds using MRS, and higher resolution of brain structures imaged with T1- and T2-based methods. The development of higher strength gradients has enabled improved signal to noise for DTI studies. Smaller coils, and coils utilizing phased-array acquisitions permit faster and higher resolution acquisitions without the need to go to higher field strength. Additional advances in software and hardware development have introduced methods to correct for head movement during scanning, which will greatly improve the quality of data derived from younger subjects, particularly those who may be unable to stay still for long periods of time, as is evident in a subset of drug exposed children.

Below we will review current brain imaging literature defining alterations in the structure of the Central Nervous System (CNS) of infants, children, and young adults following prenatal exposure to cocaine, methamphetamine, marijuana, alcohol, and tobacco. For each of these drugs we will introduce the topic with a discussion highlighting some of the mechanisms thought to underlie their neuro-teratogenic effects. Neither the discussion of the mechanism of action nor the review of imaging findings in offspring following such prenatal drug exposures is exhaustive, but rather are geared to provide insights to better educate both researchers studying and clinicians caring for such infants and children. 


\section{NEUROIMAGING OF PRENATAL EXPOSURE TO COCAINE}

\subsection{Background}

Beginning in the 1980s, cocaine (benzoylmethyl ecgonine) became one of the most frequently abused illicit drugs during pregnancy 1 and also one of the most studied with regards to its potential neuro-teratogenic effects on the developing fetus and child. While early catastrophic predictions about the fate of prenatally cocaine-exposed children proved unfounded, concerns remain about "subtle" effects 2 that may heighten the risk for sub-optimal developmental outcomes, particularly as children age and manifest more nuanced cognitive and behavioral functioning.

There are several pathophysiologic pathways through which prenatal exposure to cocaine may influence early brain development. The first major pathway involves the direct effects of cocaine on brain neurotransmitter systems. Because monoamine (MA) neurotransmitter receptors (NA, 5-HT and DA) are present early in corticogenesis, areas highly expressing these neurotransmitter systems may be especially susceptible to elevated synaptic MA levels secondary to cocaine's main effect of blocking catecholamine reuptake at the presynaptic level $^{3-5}$. In particular, as MA neurotransmitters play a key trophic role in brain development ${ }^{6}$, prenatal cocaine may alter normal mechanisms that modulate neuronal growth $^{3}$. In the rabbit model, prenatal cocaine causes a functional uncoupling of the dopamine $\mathrm{D}_{1}$ receptor from its G-protein in cortical and subcortical areas, and associated cytoarchitectural alterations in excitatory pyramidal neurons and inhibitory interneurons ${ }^{7}$. Other cytoarchitectural alterations have been observed in mouse, rat and non-human primate models $8-10$. Additional less well understood mechanisms by which cocaine may directly impact early brain development include its interaction with other neurotransmitters, including GABA and glutamate ${ }^{11-13}$ and its effects on altering gene expression ${ }^{8}$, including dopaminergic and serotonergic systems ${ }^{14}, 15$, as well as multiple apoptosis-associated genes 16 .

The second major pathophysiologic pathway involves cocaine's vasoconstrictive effects, which may indirectly impact fetal brain development through alterations in placental vasculature, elevations in plasma catecholamines ${ }^{17}$, and decreased placental blood flow 18 . These in turn can reduce the supply of oxygen and nutrients to the fetus which can contribute to intrauterine growth restriction ${ }^{19}$, hypoxemia, and in a small number of cases large vesseldistribution strokes 20,21 . Others working in the field ${ }^{22}$ have shown that, at least in the mouse model, prenatal cocaine-induced CNS alterations are not mediated through maternal vasoconstriction.

Finally, a third major pathophysiologic pathway, fetal programming, has recently been proposed $^{23}$ in which prenatal cocaine exposure may alter the expression of key candidate genes and gene networks important to placental function in late gestation. Two of the proposed candidate placental genes include norepinephrine transporter (NET) and 11-ßdehydroxysteroid dehydrogenase type 2 (11ß-HSD-2), both of which modulate the fetal neuroendocrine environment by controlling catecholamine and glucocorticoid levels. Alterations in the expression of these genes and downstream effects on placental gene networks are hypothesized to cause developmental dysregulation in the HPA axis and subsequent longterm neurobehavioral effects.

In clinical studies, prenatal cocaine exposure has been associated with a wide range of subtle effects including small but significant decreases in fetal growth, increased rates of intrauterine growth retardation, early impairments during both the neonatal period and infancy in arousal, self-regulation, acoustic cry characteristics, and motor development. More recently, long-term problems have been identified in children prospectively followed through the age of 15 years, 
including deficits in intelligence, language skills, executive functioning, impulse control and attention, and evidence of internalizing and externalizing behavioral traits $23-25$. For the MRI studies, the cohorts of children with and without prenatal exposure to cocaine are determined based on self-report and drug screening (e.g., urine-toxicology, hair radioimmunoassay, meconium analysis). Here we review what T1-weighted anatomical MRI, DTI, fMRI and MRS studies in these children have told us about the effects of prenatal cocaine exposure.

\subsection{Neuroimaging Studies of Prenatally Cocaine-Exposed Children}

T1-weighted anatomical MRI can be used to qualitatively determine a variety of structural abnormalities. Structural MRI of infants and children exposed to cocaine in utero have revealed cortical infarcts, pachygyria, schizencephaly $26-28$, and an increased incidence of periventricular hemorrhage, subependymal and periventricular cysts $29-31$,

T1-weighted MRI can also be used to quantitatively detect more subtle effects. A number of studies have reported MRI-based volumetric brain data from children with prenatal cocaine exposure. Volumes of the following regions have been investigated: cortical gray matter, white matter, subcortical structures, corpus callosum and cerebellum.

Behnke et al. found a significant decrease in the volume of right anterior cerebellum in cocaineexposed children ${ }^{32}$. On the other hand, Singer et al. reported decreased gray matter volume in right parietal and left occipital lobes in cocaine-exposed children ${ }^{32}$. Singer et al. also found a decrease in the area of corpus callosum. The cerebral lobes and cerebellum were labeled and quantified by these investigators using an Automatic Non-Linear Image Matching and Anatomical Labeling (ANIMAL) tool. The amount of cocaine exposure was predictive of the total area of corpus callosum and, although the cocaine-exposed children were also exposed to more cigarettes and alcohol, the volumetric decrease remained significant after adjustment for other exposures. These investigators hypothesized that observed morphologic abnormalities may have been caused by vascular injury or anterior corpus callosum agenesis as a result of exposure to toxins. Changes in grey matter volume in the occipital and parietal lobes did not show a dose-dependent response. In addition, gray matter volume of the right parietal lobe was shown to correlate with visual attention, visual-motor performance, sensorimotor ability and syntax construction scores at 6 years of age. Grey matter volume of the left occipital lobe was shown to correlate with visual motor performance scores at 6 years of age as well as with neonatal visual attention and visual recognition memory when 12 months old. The above findings (by Behnke and Singer) were presented during a symposium at the annual meeting of the Neurobehavioral Teratology Society but have yet to be published.

Avants et al. reported a decrease in caudate volumes in cocaine-exposed children ${ }^{33}$. The cocaine-exposed children were also exposed to marijuana, tobacco and alcohol but not to methamphetamine. These poly-substance effects were not separately analyzed but the subjects were all right handed, socio-economically matched with no significant difference in IQ scores or gender.

A recent study from our group reported MR volumetric decreases in cortical gray matter, thalamus and putamen 34 in prenatally cocaine exposed children when compared with a group of children, who were not exposed to cocaine. The groups were matched on age and IQ, and significant differences remained after controlling for gender. Furthermore, we observed an inverse relationship between the exposure level and the thalamic and putaminal volumes. Both groups were exposed to marijuana, tobacco and alcohol but not to methamphetamine. No correlation was seen between alcohol or tobacco exposure and structure volumes, but a reduction in the putaminal volume was noticed in two heavily alcohol-exposed subjects, neither of them exposed to cocaine. When these subjects were removed from the control group, the significance in putaminal volume changes remained. 
Finally, Rivkin et al. reported ${ }^{35}$ lower mean cortical gray matter and total parenchymal volumes. While this study did not assess dose-response with respect to cocaine, after covarying for other drugs, the effects of cocaine on brain volumes lost significance.

Overall, these volumetric T1-weighted MR studies suggest that prenatal cocaine exposure is associated with long-term morphological CNS changes, and that these may correlate with functional outcomes. For example, both caudate and putamen receive dense dopaminergic innervation, and changes in their morphology may underlie difficulties in attention that some children with prenatal cocaine exposure experience. Likewise, alterations in the thalamus have been hypothesized to underlie subtle learning difficulties that children with prenatal cocaine exposure may encounter ${ }^{36}$. Finally, as the Rivkin paper describes, demonstrated changes in cortical gray matter may be due to the presence of poly-substance confounds and not consequent to prenatal cocaine exposure alone.

The impact of prenatal cocaine exposure on the developing CNS has also been studied using DTI and MRS. Warner et al. found increased ADC in the left frontal callosal and the right frontal projection fibers among exposed children in comparison to a socio-economically matched comparison group, however, no significant differences in FA were identified ${ }^{37}$. These six-directional DTI images were acquired on a 3T Siemens scanner and the ADC outcomes were controlled for age and gender. A study utilizing MRS showed increased creatine $(\mathrm{Cr})$ in the frontal white matter with normal N-acetylaspartate (NAA) and the absence of any observable brain abnormalities on structural MRI ${ }^{38}$. The investigators hypothesized that the increased $\mathrm{Cr}$ may reflect altered energy metabolism or glial proliferation. The frontal white matter findings in both of these studies are consistent with an underlying mechanism of intrauterine hypoxia, which is one of the most commonly identified mechanisms explaining the consequences of prenatal cocaine exposure ${ }^{38-40}$.

Rao et al. reported 10\% decrease in global cerebral blood flow (CBF) in adolescents with prenatal cocaine exposure ${ }^{41}$. They observed a relative increase in CBF in anterior and superior brain regions and suggested that this may be due to development of compensatory mechanisms for reduced global cerebral blood flow during neural ontogeny. Their findings were based on the MRI scans of 25 cocaine-exposed and 24 control subjects (average 14 years old). The perfusion fMRI scans were acquired using arterial spin labeling (ASL).

Hurt et al. reported similar results in a fMRI study of 17 prenatally cocaine-exposed and 17 non-exposed adolescences, with an average age of 14 years, performing an executive function $\operatorname{task}^{42}$.

Finally, Sheinkopf and colleagues recently investigated fMRI brain activation patterns in 12 prenatally cocaine-exposed and 12 non-exposed comparison school-aged children (8-9 years of age) using a variant of the $\mathrm{Go} / \mathrm{No}$ Go response inhibition task ${ }^{43}$. While no group differences were noted in task performance, the exposed children showed greater BOLD signal activation in frontal and striatal regions, contrasting with greater activation among non-exposed children in the occipital cortex and fusiform gyrus, suggesting functional differences in neural systems underlying cognitive control and attention.

In conclusion, recent advances in MRI have greatly contributed to our understanding of prenatal cocaine exposure effects on the developing human brain. Longitudinal studies with careful control of other factors (exposure to other drugs, maternal care, socio-economic status) need to be conducted on larger sample sizes. Correlations between clinical data and structural, metabolic, functional and diffusion MR images will provide further insights into the underlying pathophysiologic basis for prenatal cocaine effects on brain structure and function. 


\section{NEUROIMAGING OF PRENATAL EXPOSURE TO METHAMPHETAMINE}

\subsection{Background}

The neurotoxic amphetamines include D-amphetamine (AMP), D-methamphetamine (METH), 3,4-methylenedioxymethamphetamine (MDMA), and p-chloroamphetamine. Since the late 1980s there has been a large increase in the use of METH ${ }^{44}$ and MDMA 45,46 including use among women of childbearing ages ${ }^{47-50}$ but there have been no long term studies of the neurodevelopmental consequences of prenatal MDMA in humans ${ }^{51}$. METH is a potent psychostimulant drug that has been shown to be neurotoxic to mature dopaminergic and serotonergic axons and axon terminal arbors 52 , and potentially neurotoxic to mature glutaminergic axons ${ }^{53}$. The cellular and molecular mechanisms implicated in the neurotoxicity induced by METH on mature neurons include the production of reactive oxygen species and nitric oxide, p53 activation resulting in apoptosis, and mitochondrial dysfunction ${ }^{54}$. Less is known about the mechanisms involved in METH-induced toxicity in the developing central nervous system. However, as mentioned above for cocaine, the early and widespread influence of serotonergic, dopaminergic and glutamatergic systems on neuronal growth and connectivity provides a strong theoretical basis for suspecting that prenatal exposure to METH and other neurotoxic amphetamines may also result in alterations in developing neural circuitry ${ }^{53}$. In a fetal rat model of low and high-dose gestational METH exposure, Weissman and CaldecottHazard produced both serotonergic neurotoxic effects and synaptic remodeling of axonal terminals ${ }^{55}$. More recently, Jeng et al. identified oxidative DNA damage in the brains of embryonic and fetal mice, along with resultant postnatal motor deficits, after exposure to a single dose of METH ${ }^{56}$.

In adult animals and humans, METH exerts its neurotoxic effects on multiple brain areas including prefrontal cortex and ventral striatum (nucleus accumbens) ${ }^{57-59}$, dorsal striatum (putamen, caudate, globus pallidus) ${ }^{60}$, hippocampus and cingulate gyrus 61 , and amygdala ${ }^{62}$. These areas of the brain are important in the development, expression and control of affect, attention, language and cognition, and social relationships, functional domains that have all been identified as potential areas of concern following prenatal psychostimulant exposure ${ }^{63-67}$. In addition to its direct neurotoxic effects, METH may alter fetal development through indirect mechanisms such as vasoconstriction 68,69 , resulting in diminished uteroplacental blood flow and fetal hypoxia ${ }^{70}$, and maternal anorexia ${ }^{71}$, resulting in intrauterine growth retardation and impaired fetal brain development ${ }^{72,73}$.

Although METH use by women of child-bearing age places fetuses at risk for exposure to this drug, the short and long-term consequences of gestational exposure to METH are only beginning to be elucidated and are still for the most part largely unknown. A group of researchers in Stockholm, Sweden has followed a cohort of 65 children since 1976 whose mothers used AMP during pregnancy. They have documented a variety of adverse physical, cognitive, emotional, and social effects in these children, including increased rates of ADHD, learning disabilities, aggression, and school failure ${ }^{74-82}$. However, multiple methodological flaws, including the lack of a control group, confounding drug exposures, and examiners not blinded to exposure status, make interpretation problematic. More recently, our group has identified subtle neurobehavioral findings 83 and increased rates of intrauterine growth restriction 84 in an ongoing prospective, controlled and blinded study of prenatal METH exposure and child development. Our longitudinal clinical study is now focused on identifiying specific endophenotype profiles (e.g., attention, motivation and memory) of prenatal METH exposure that, if identified, have the potential to enhance our understanding of the underlying pathophysiology and will provide powerful behavioral correlates to structural and functional brain imaging data. 


\subsection{Neuroimaging Studies of Prenatally Methamphetamine-Exposed Children}

Only two MRI studies were identified in the literature that have evaluated changes in the brains of infants and children exposed prenatally to METH. The first study by Smith et al., reported on the use of MRS to evaluate neurochemical alterations in children exposed prenatally to METH and a control group of non METH-exposed children ${ }^{85}$. MRS allows for the assessment of neuronal and glial integrity and function, energy metabolism, and neurotransmission, and has been used to evaluate chemical alterations in normally developing children $86-89$ and in children with developmental delays 90 , autism 91,92 , ADHD 93,94 , and other conditions 95 , 96. In the Smith et al. study, children in the METH-exposed group also had prenatal tobacco (6/12) and alcohol (4/12) exposure; none of the control group were identified as alcohol exposed and only $1 / 14$ was exposed prenatally to tobacco. Significant increases in total creatine in the basal ganglia of the METH-exposed group was noted, suggesting possible alterations in cellular energy metabolism, however, no differences were found in $\mathrm{N}$-acetyl-containing compounds, a marker of neuronal damage or loss.

The second study, done by the same group 97 , assessed volumetric differences in multiple brain regions among METH-exposed children compared to non METH-exposed children. Similar to their MRS study, 6/13 METH-exposed children had prenatal tobacco exposure and 2/13 had prenatal alcohol exposure; among the control group 1/15 children had prenatal tobacco exposure and none were reportedly alcohol-exposed. Correcting for multiple comparisons, significant volumetric reductions were noted in several subcortical areas in the METH-exposed group (globus pallidus, putamen and hippocampus). Although no interaction effects were found between METH exposure status, brain volume, and neurocognitive performance, when both METH-exposed and -unexposed groups were combined, volumetric decreases in these three structures were associated with poorer performance on sustained attention (Test of Variable Attention) and delayed verbal memory (California Verbal Learning Test for Children) tasks.

It is premature to conclude that these findings are definitive METH effects, given the small sample sizes and the potential confounds of uncontrolled drug exposures, medical and sociodemographic conditions. For instance, as summarized below, there is accumulating evidence that prenatal nicotine exposure in and of itself may be related to structural changes in the developing brain 35,98 , and prenatal alcohol exposure has been clearly linked to a wide range of neurostructural alterations ${ }^{99}$. The further problem of differentiating actual causal processes from epiphenomena and compensatory responses is also present in these cross-sectionally designed studies ${ }^{100}$. Nevertheless, these studies suggest that subcortical brain structures and prefrontal-striatal circuitry involved in attention and memory ${ }^{101-103}$ may be impacted adversely by the neurotoxic effects of METH on developing neural systems.

\section{NEUROIMAGING OF PRENATAL EXPOSURE TO MARIJUANA}

\subsection{Background}

Marijuana is the most commonly used illicit drug during pregnancy ${ }^{104}$, yet like other drugs of abuse the preponderance of studies have focused on birth and early childhood outcomes and relatively little research has examined the long-term neurodevelopmental consequences of gestational marijuana exposure ${ }^{105}$.

Cannabinoids, including marijuana and its primary pharmacologically-active alkaloid, delta-9tetrahydrocannabinol (THC), exert their psychoactive effects on multiple brain regions in concert with multiple neurotransmitter systems, including dopaminergic, GABAergic, glutaminergic, and cholinergic systems ${ }^{106}$. Like other drugs of abuse, including cocaine, amphetamines, opiates, nicotine and alcohol, the cannabinoids produce their rewarding effects primarily by increasing dopamine release in the nucleus accumbens, a major terminal field of the mesolimbic dopamine system ${ }^{106}$. Proposed mechanisms include both direct effects of 
cannabinoids on dopaminergic neurotransmission in the nucleus accumbens, and indirect effects of cannabinoids on brain CB1 cannabinoid receptors causing the release of endogenous opioids, which then act on opioid receptors in the VTA causing release of dopamine in the nucleus accumbens ${ }^{107}$. In addition to these mechanisms, however, there has been increasing recognition of the role that exogenous and endogenous cannabinoids may play in CB1 receptormediated synaptic transmission and synaptogenesis in the adult CNS ${ }^{108}$, and, more important to this review, in the regulation of multiple aspects (e.g., neuronal proliferation, migration, differentiation, survival, and synaptogenesis) of prenatal CNS development ${ }^{109}$. The early and widespread distribution of cannabinoid receptors in the fetal and neonatal brain, at levels that appear to exceed those seen in the adult CNS ${ }^{110}$, and the important physiological role that CB1 receptors play in GABA-driven cortical network activity 111 , raises concern regarding potential effects of prenatal marijuana exposure on fetal and subsequent brain development.

In clinical studies, prenatal marijuana exposure has been associated with alterations in newborn and infant state regulation 112,113 , deficits in short-term memory, and verbal and abstract/ visual reasoning among preschool and early school-age children $114-116$, and statistically smaller head circumference at ages 9-12 years among children born to heavy marijuana users ${ }^{117}$. In contrast to the more global developmental impairments seen with prenatal alcohol and nicotine exposure, prenatal marijuana exposure has been shown to result in selective executive function (EF) deficits in discrete areas such as complex visuo-perceptual tasks ${ }^{105}$, sustained attention 118 , and hyperactivity, impulsivity, and delinquency 119,120 . These and other findings have led researchers to hypothesize that the effects of prenatal marijuana exposure on higher cognitive functions are mediated preferentially through the prefrontal cortex, and its connections with other parts of the brain 105,121 .

\subsection{Neuroimaging Studies of Prenatally Marijuana-Exposed Children}

There is little data documenting structural brain changes as a result of prenatal marijuana exposure. In a recent volumetric MRI study of 10-14 year old children with and without intrauterine exposure to cocaine and other drugs of abuse, cortical gray matter was reduced in the marijuana-exposed children, but he model used was not adjusted for age, gender and other drug exposures ${ }^{35}$. Another recent study, using DTI to assess frontal white matter development in children with prenatal cocaine exposure, found that intrauterine exposure to both cocaine and marijuana resulted in higher (worse) mean diffusivity than exposure to cocaine alone 37 . Finally, in a study of adult subjects, initiation of marijuana use prior to age 17 years was associated with reductions in whole brain and percent cortical gray matter volumes and increased percent white matter volume, suggesting the possibility that marijuana exposure during developmentally sensitive periods is required to produce structural CNS alterations ${ }^{122}$. The limited findings of these studies are paralleled by the general lack of association between marijuana use and structural brain abnormalities in adults 123,124 .

Two fMRI studies, both from the same group of investigators, have examined the relationship between prenatal marijuana exposure and adolescent/young adult neural functioning during tasks requiring response inhibition and visuo-spatial working memory, while controlling for covariates such as IQ, prenatal nicotine, alcohol and caffeine exposure, and current marijuana, nicotine and alcohol use $\mathrm{e}^{121,125}$. In the first study, subjects with and without prenatal marijuana exposure underwent fMRI while performing a two condition Go/No-Go task. There were no significant group differences for reaction time and errors of omission for either condition, however the prenatally exposed group had significantly more errors of commission on the more difficult of the two tasks. The amount of prenatal marijuana exposure was significantly positively related to bilateral prefrontal cortex (PFC) and right premotor cortex activity, and significantly negatively related to left cerebellar activity, suggesting to the authors the possible need for increased effort to perform the task, perhaps as a compensatory response 
to altered or delayed development of the PFC or a larger neural system involving these three brain regions. In the second study, fMRI was conducted on the same subjects during a visuospatial 2-back test. There were no significant performance differences between the prenatally exposed and unexposed groups. However, as in the previous study, the amount of prenatal marijuana exposure was significantly positively related to increased activity in the left medial PFC, the left inferior frontal gyrus, and the left cerebellum, and significantly negatively related to activity in the right dorsolateral, medial, and ventral PFC, left pre-supplemental motor cortex, and the right parahippocampal gyrus. The authors speculated that prenatal marijuana exposure may have altered the lateralization and functional connectivity of multiple brain regions, which, along with the PFC, are important in the performance of a complex EF task.

\section{NEUROIMAGING OF PRENATAL EXPOSURE TO ALCOHOL}

\subsection{Background}

Prenatal exposure to alcohol (PEA) can cause serious disruptions in growth and maturation within the developing human brain. As early as 1973, Jones et al. coined the term fetal alcohol syndrome (FAS) characterized by a triad of features: 1) Growth deficiencies that are prenatal in origin; 2) A dysmorphic facial appearance with specific craniofacial anomalies typical of FAS (i.e., indistinct philtrum, thin vermillion border, and small palpebral fissures), and 3) Evidence for brain dysfunction ${ }^{126}$. Recently, "Fetal Alcohol Spectrum Disorders" (FASD) has been designated as a non-diagnostic, 'umbrella' terminology to encompass the complete spectrum of effects with or without facial dysmorphisms resulting from PEA. FASD currently affects as many as one percent of all live births in the US ${ }^{127}$.

Since FAS was first described, more than 25 years ago, the molecular and cellular mechanisms through which PEA is thought to exert its detrimental effects on the developing brain have been slowly elucidated, with significant progress made over the last decade. Initial findings highlighted the regional vulnerability of specific brain structures, including the neocortex, cerebellum and hippocampus, to ethanol-induced neuronal cell loss 128,129 . Subsequently, researchers determined that prenatal alcohol exposure alters maturation of glial cells ${ }^{130}$, and that this is associated with failure of neuroblasts to migrate to their proper targets ${ }^{131}$, suggesting that alcohol-induced impairment of neurogenesis and neuronal migration contribute to alterations in brain size and cortical architecture. More recent studies have emphasized the relevance of alcohol-induced cell necrosis and enhanced natural apoptosis, mediated by glutamatergic antagonism at the NMDA receptor and GABA-mimetic actions at the GABAA receptor ${ }^{132}$. Additionally, a number of other factors have been implicated as potential contributors to the neurotoxicity of prenatal alcohol, including nutritional ${ }^{133}$ and socioeconomic factors ${ }^{134}$, genetic susceptibility linked to polymorphisms in alcohol and aldehyde dehydrogenase, and the serotonin transporter gene promoter (5-HTTLPR) ${ }^{135}$, alcohol-induced hypoxia ${ }^{136}$, alcohol-induced free radical production ${ }^{137}$ and inhibition of cell adhesion mediated by the human L1 gene ${ }^{138}$. How these potential mechanisms contribute individually and collectively to altered brain growth and maturation resulting from alcohol exposure has so far not been clearly established, and additional mechanisms may be operative with specific developmental consequences (for review, see Guerri ${ }^{139}$ ). The subsequent paragraphs briefly review the neuroimaging literature in subjects with PEA.

\subsection{Neuroimaging Studies of Prenatally Alcohol-Exposed Children}

Neuroimaging studies have consistently cited overall decrements in total cranial, cerebral and cerebellar volumes in FAS subjects ${ }^{140-143}$. Using segmentation and parcellation techniques, Archibald and colleagues reported volume reductions in parietal, temporal and frontal lobes of the FAS group, with only parietal region showing statistically significant volume reduction after accounting for the overall reduced brain volume. The study had age matched control 
subjects. No significant volume differences were noted amongst the non-dysmorphic FASD subjects ${ }^{140}$. A disproportionate cerebral and cerebellar WM volume reduction, pointing towards greater involvement of WM than the gray matter, was noted in FAS subjects. The cerebellar WM volume reduction however did not reach statistical significance ${ }^{140}$.

Sowell et al. reported an average volume reduction of $12 \%$ in subjects with PEA, as compared to control subjects ${ }^{144}$. Using voxel-based morphometric analyses, Sowell et al. demonstrated greater volume reductions in the posterior temporal and parietal lobes in FASD group ${ }^{142}$. In a subsequent volumetric study, these findings were consistently replicated ${ }^{143}$. Using whole brain surface analyses, regional shape differences in an FASD group were studied and compared with matched controls. This method measures the distances from the center (DFC) or distances from a particular point on the anterior commissure to specific landmark points in different brain regions. In the PEA group, the DFC on both sides of the inferior parietal regions were less than those of the control group, causing these regions to look "narrow". Also, the DFC to landmarks on the cortical surface of the left orbito-frontal cortex were shorter in FASD subjects, creating a "blunted" effect in the frontal lobe. Sowell et al. also observed structural irregularities corresponding to either an increase in gray matter density, and/or in WM volume reductions. Density maps within both the parietal lobes, especially the left hemispheric, showed reduction in lobar volumes, with increased gray matter and decreased WM densities.

Further study of hemispheric asymmetry patterns using cortical matching techniques applied to the PEA group showed significantly reduced "right to left" gray matter ratios in posterior temporal lobes of subjects with PEA compared to controls. Increase in gray matter density was observed in the inferior parietal and superior temporal lobes, while WM hypoplasia was most prominent in the perisylvian and inferior parietal regions. An inverse relationship of regional volume with gray matter density was observed ${ }^{145}$. The authors suggest that neurocognitive deficits in language processing, and object and face recognition frequently found among subjects with PEA can be explained by parietal lobe involvement. Additionally, the frontal and parietal lobe abnormalities may explain impairments in executive functions, spatial memory and reduced response inhibition often seen in individuals with PEA ${ }^{146}$.

Using cortical pattern matching algorithms and techniques for measuring cortical thickness in the same cohort mentioned earlier, Sowell et al. reported significant cortical thickness excesses, up to $1.2 \mathrm{~mm}$, in bilateral temporal, inferior parietal and right frontal regions in the PEA group when compared to control subjects. Verbal recall and visuo-spatial measures correlated strongly with the right dorsal frontal and left occipital region thicknesses, respectively ${ }^{147}$. It should be noted that gray matter density and cortical thickness are not identical measures, as each provide unique and independent information. Gray matter density essentially reflects the proportion of tissue that has gray matter signal value on MRI, relative to other tissue types. Cortical thickness, however, reflects regional structural integrity. It is a specific measure of cortical anatomy, reflecting intrinsic alterations within the gray matter, and is unaffected by sulcal widening or other CSF related effects ${ }^{148}$. With progressive myelination, pruning of synaptic connections and, consequently, cortical thinning, occurs during normal brain development and maturation ${ }^{149}$. The findings of this study provide evidence that synaptic pruning and myelination may not be occurring normally, or may be disrupted in children with PEA.

The CC (corpus callosum) is an interhemispheric WM tract connecting the two cerebral hemispheres, which plays an important coordinating role for various functions like bimanual motor tasks, interhemispheric information transfer, and sustained attention. Its role in visual and spatial working memory is well recognized. CC hypoplasia, including significant volume reductions in both anterior and posterior CC regions, has been frequently reported in subjects with PEA $141,144,150,151$. 
A similar study, using a subsample of the earlier study, found not only significant reductions in the area of posterior CC (splenium), but also marked inferior and anterior displacement in the FASD group compared to controls. Among the non-dysmorphic FASD subjects, this displacement of the splenium was less than that for the FAS group and the amount of CC displacement correlated well with impairment in verbal learning ability, suggesting that $\mathrm{CC}$ displacement is a better predictor of verbal learning than the regional CC area 144 .

Bookstein et al. used novel shape-based CC morphology representations and found that alcohol-exposed subjects showed greater $\mathrm{CC}$ shape variability compared to matched controls. This shape-based analytical technique offers the advantage of overcoming the problem of spatial correction required for microcephaly, a common feature of FASD ${ }^{152}$. These studies demonstrate a differential sensitivity of certain CC sections to PEA. Additionally, it was found that "thick" CC (blunted anterior CC portion with less projection into the frontal regions) correlated with poorer executive functioning, perhaps owing to impaired connectivity of the WM tracts in the anterior CC to the brain regions involved in executive functions, while "thin" $\mathrm{CC}$ was related to motor deficits, probably because in this case, the connecting tracts within the CC may be less efficient in relaying information to motor centers 153 .

DTI provides another imaging technique for evaluating WM integrity of the CC. Decreases in FA with increases in ADC were observed in the genu and the splenium of the CC of the alcoholexposed group, compared to controls, findings that point to WM microstructural changes as a result of PEA. Altered FA and ADC did not correlate to any specific neurocognitive deficits 154 .

A small study showed that FASD subjects had greater mean diffusivity (MD) in the isthmus of $\mathrm{CC}$, with no significant differences in the other $\mathrm{CC}$ regions. MD represents average water diffusion in all directions ${ }^{155}$. In another study, WM integrity following PEA was evaluated and compared with matched controls, using DTI and T1-weighted MRI images, and their correlation with neurocognitive deficits ${ }^{156}$. Lower values for FA were observed in the FASD group in right lateral temporal lobe and bilaterally in lateral aspects of the splenium of CC. WM density was found to be low in some, but not all of these regions with low FA. The areas with low FA were confirmed to be WM using region of interest (ROI) analyses, suggesting that PEA may be associated with decreased myelination or disorganized WM tracts. The FA of the splenium, but not that of the temporal lobe correlated with scores of visuo-motor integration tests 156 . Another study found impairments in tasks related to interhemispheric information transfer in children with PEA, and showed that these impairments correlated with reductions in the size of $\mathrm{CC}^{157}$. These abnormalities in $\mathrm{CC}$ may correlate with certain functional impairments in executive functions, attention span, coordination, and verbal learning abilities often seen in individuals with PEA.

The cerebellum has been associated with several motor functions including maintenance of posture, coordination and balance. Its role in attention and classical conditioning has also been well described ${ }^{158}$. Neuroimaging studies have consistently reported reductions of cerebellar volume and surface area in subjects with PEA 140,141 . Within the cerebellum, several studies have observed regional specificity of alcohol effects $1 \dot{4} 1,159$. Abnormalities in balance, coordination and attention observed commonly in subjects with PEA can be neuroanatomically correlated to the cerebellar abnormalities.

Autti-Ramo et al. applied image analyses to structural MRI and studied the brain morphological alterations caused by PEA. Out of the 17 children with PEA in this study, hypoplasia of the vermis was observed in 10 children and one had malformed posterior vermis. Five children had hypoplastic cerebellar hemispheres. Hypoplasia of the corpus callosum was observed in two children. Small hippocampi were observed in three children and wide cortical sulci in six. 
No particular structural anomaly correlated specifically with neuropsychological deficits, but abnormal development of cerebellar vermis was found the most sensitive morphological indicator for PEA effects ${ }^{141}$.

Sowell et al. measured the area of cerebellar vermis from brain MRI of children and young adults with prenatal alcohol exposure. From the midsagittal MRI section, three vermal areas were circumscribed: anterior vermis (vermal lobules I-V), posterior vermis (vermal lobules VI and VII), and the remaining vermal area (including lobules VIII-X). Both FAS subjects as well as the non-dysmorphic subjects with PEA showed significant volume reductions in the anterior cerebellar vermis (lobules I-V). The volume differences remained significant even after controlling for overall reductions in brain size. These findings point to an abnormal pattern of brain development in the anterior vermal region, with apparent sparing in the posterior vermal region subsequent to PEA, suggesting that regionally specific Purkinje cell death may be occurring in humans prenatally exposed to alcohol 159 .

O'Hare et al. applied surface-based image analytic methods to T1-weighted MRI series and correlated the findings with neuropsychological measures in PEA group and compared them with matched controls. The morphology of the cerebellar vermis was characterized and potential cognitive correlates of vermal morphology evaluated. In the PEA group, the anterior and superior edges of anterior vermis appeared to be displaced by 1-3mm in FAS individuals, while the FASD (non-dysmorphic subjects with PEA) showed less prominent displacement $(1.4 \mathrm{~mm})$. Anterior vermal dysmorphology was negatively correlated with verbal learning and memory performance within the alcohol-exposed group. These observations localize the specific pattern of cerebellar vermal dysmorphology following PEA with selective involvement of the anterior vermis, an earlier developing cerebellar region, and with sparing of the later developing cerebellar regions 160 .

Neuroimaging data provides inconsistent evidence as to whether hippocampal development is impacted in individuals with PEA $140,141,161$. A small study reported asymmetric hippocampal size following PEA, with right hippocampal volumes larger than left, however the study was not case controlled 161 . Other studies report relative sparing of hippocampus and amygdala following PEA, especially when whole brain volumes are taken into account 140 , 162. The hippocampus and amygdala are components of the limbic system and are functionally implicated in formation of long term memories and emotion, respectively. Considering their functional implications, further studies clarifying the involvement of these structures following PEA are warranted. Several studies have reported disproportionate volume reductions of the BG (basal ganglia) in subjects with PEA. However, when overall brain volume was taken into account, only reductions in caudate volume remained significant $140,162,163$. The volumes of lenticular and accumbens nuclei were relatively spared $140,163$.

A fMRI study in adolescents and young adults with PEA found significant reductions in metabolic activity in the thalamus, caudate heads and the right caudate and putamen bodies as compared to controls ${ }^{164}$. Cortese et al. reported MRS findings in a small group of children with PEA. The caudate nucleus was not only found to be significantly smaller in the group with PEA, but the metabolite ratio of NAA to $\mathrm{Cr}$ was also found to be elevated in the left caudate nucleus compared to controls 165 . Elevated NAA/Cr was found to be secondary to NAA elevations, raising the possibility of deficient apoptosis, dendritic pruning or myelination in the FASD group ${ }^{165^{\circ}}$.

Riikonen et al. studied a small population of children with FAS using MRI and single photon emission computed tomography (SPECT) to find specific brain regions of vulnerability following PEA ${ }^{161}$. Morphological anomalies were observed in 6 of 11 patients by MRI and were both cortical and subcortical. Additionally, volumetric studies of the hippocampus 
showed morphological left-right asymmetry in 5 of 8 patients with PEA. SPECT however showed only mild hypoperfusion of the left hemisphere in all subjects. The negative left-right index was located especially in the left parieto-occipital region, an area implicated in arithmetical and logical functioning. Normal left-right dominance was also lacking in the frontal area, an area that is also affected in attention deficit hyperactivity disorder (ADHD). This suggested to the authors that functional anomalies may be more common than structural abnormalities as a result of PEA in a developing brain ${ }^{161}$.

In conclusion, the recent advances in brain imaging have greatly contributed to our understanding of prenatal alcohol exposure effects on the developing human brain and have consistently demonstrated involvement of specific brain regions with sparing of other areas, highlighting the regional vulnerability of the brain to alcohol's detrimental effects.

\section{NEUROIMAGING OF PRENATAL EXPOSURE TO TOBACCO}

\subsection{Background}

The burden of prenatal exposure to maternal cigarette smoke (PEMCS) is high, with more than half of the tobacco smoking women continuing to smoke through their pregnancies, resulting in annual births of approximately half a million infants with PEMCS, within the US alone. The overall prevalence of smoking among pregnant women has been estimated to range from $10-50 \%$, with 10-16\% women in United States continuing to smoke during pregnancy $166-168$.

Nicotine is the primary psychoactive component of tobacco smoke. Prenatal nicotine exposure may adversely impact fetal brain development through both indirect and direct mechanisms. Potential indirect mechanisms include maternal and fetal undernutrition secondary to smokinginduced anorexia, hypoxia due to increased carboxyhemoglobin and vasoconstriction, placental hypertrophy and reduced transplacental transport of nutrients ${ }^{169}$. Preclinical studies in rodents and primates have demonstrated the direct effects of fetal nicotine exposure on brain and body growth parameters and have shown that nicotine is a neuro-teratogen that targets several neurochemical systems, particularly $\mathrm{NE}^{170}$. Nicotine binds to nicotinic acetylcholine receptors (nAChRs) which become detectable during the embryonic development shortly before neurulation ${ }^{171}$. Acetylcholine (ACh) plays a crucial role in brain development and maturation, initially promoting cell division and subsequently promoting a switch from cell replication to differentiation. Stimulation of $\mathrm{nAChRs}$ by nicotine during gestation disrupts brain development, by altering these trophic effects of Ach ${ }^{170,172}$. These neurodevelopmental effects appear to be highly selective for particular brain regions ${ }^{172}$. Preclinical studies have also demonstrated changes in other monoamine systems following prenatal nicotine exposure. Dopamine synthesis and turnover is decreased in the forebrain and brain stem 173,174 , striatal and VTA dopamine content is reduced, and striatal $\mathrm{D}_{2}$ receptor binding is decreased in rats exposed to nicotine ${ }^{175}$. Serotonin synthesis and turnover is likewise decreased in the forebrain and brain stem of exposed rats 174 . In addition, serotonin transporter density is increased in brain stem and decreased in forebrain regions with prenatal nicotine exposure ${ }^{176-178}$.

Despite the widespread prevalence of smoking among women, the exact effects of PEMCS on the developing human brain are as yet not fully understood. Indirect clinical evidence points to the detrimental effects of PEMCS on the fetal brain. A significant negative correlation between PEMCS and the head circumference at birth has been reported 34, 179, 180. Several clinical studies have reported an association of PEMCS with increased incidence of ADHD, externalizing and conduct disorders, criminal behavior, higher rates of aggression, and also an increased incidence of experimenting with, and, developing addiction to cigarette smoking during adolescence ${ }^{181-183}$. Nevertheless, a causal relationship between PEMCS and 
externalizing disorders is not definitive, as unmeasured genetic and environmental confounds may largely explain the association ${ }^{184}$. Language delay, impaired attention and visuo-spatial memory deficits following PEMCS have also been reported ${ }^{185-188}$.

Only a handful of studies have reported neuroimaging findings in subjects with PEMCS. Neuroimaging studies in subjects with PEMCS point to brain region-specific and genderspecific effects of nicotine. The ensuing paragraphs briefly review the current literature on neuroimaging findings in subjects with PEMCS.

\subsection{Neuroimaging Studies of Prenatally Tobacco-Exposed Children}

Small head size following PEMCS has been consistently reported, indirectly pointing to reduced cranial volume consequent to PEMCS ${ }^{34,179,180}$. Prenatal exposure to nicotine upregulates nicotinic cholinergic receptors within the developing brain, and shortens the proliferative phase of brain development, thereby possibly allowing earlier onset of neuronal differentiation, which may ultimately result in a smaller brain volume ${ }^{172,189}$.

The corpus callosum (CC) is a tract of fibers connecting the two cerebral hemispheres and forming the roof of the lateral ventricles. Although the $\mathrm{CC}$ is fully formed at birth, additional axons continue to pass through this structure, forming new connections well until the third decade of life.

A significant reduction in the overall CC size as compared to the control group was reported by Paus et al. using T1-weighted MRI images from PEMCS group ${ }^{190}$. Reduced CC size was observed only in females, being most pronounced in the posterior third of CC (isthmus and splenium). The posterior third of CC mainly contains interhemispheric fibers forming parts of ventral and dorsal visual streams, and the small sized CC could be consequent to abnormalities in these interhemispheric fibers ${ }^{191}$. A subset of children in this study were subjected to magnetization transfer image acquisition. No effect of PEMCS on the magnetization transfer ratio based myelination index was demonstrable within any of the sections of $\mathrm{CC}$, which implies that PEMCS specifically affects the size, but not the myelination of CC, possibly by interfering with the addition of axons during brain development. The authors suggest that the clinical ramifications of these findings may help explain the increased incidence of ADHD and association of PEMCS with impaired processing of visual stimuli.

Toro et al. compared cortical thickness in T1-weighted MRI images of adolescent subjects with and without PEMCS 98 . Cortical thickness, as measured by volumetric MRI studies, reflects the volume of various cellular components comprising the cortex. In a region-based analysis, the orbito-frontal (OFC), middle frontal and the parahippocampal cortices of the exposed group were found to be thinner compared to the unexposed group, with differences being significant only in females, in whom the thickness of OFC also correlated negatively with self rated assessment of caring. Vertex-based analysis confirmed thinner cortices in exposed group, with maximal thinning at vertices constituting the left lateral OFC in females. The authors hypothesize that thinning of OFC likely reflects nicotine induced dysregulation of the serotonergic and the cholinergic systems with subsequent decrease in activity-triggered neuronal (dendritic) and glial growth, an effect that may persist well beyond the fetal period, modifying the various neural maturational changes during childhood and adolescence ${ }^{192}$. This regional specificity of the PEMCS effects on the OFC and middle frontal cortex are consistent with the high concentration of nicotinic receptors found in these regions. The OFC and prefrontal cortex play an important role in social interaction and behavior, and their involvement may explain the high prevalence of social and behavioral problems frequently reported to occur in adolescents with PEMCS 193. 
Changes in FA reflect maturational increase in cell packing density, fiber diameter, directional coherence and myelination ${ }^{195}$. Accordingly, FA within the white matter tracts increases with age in children and adolescents, and correlates with cognitive abilities ${ }^{196,197}$. Using DTI, evidence for WM microstructural alterations has been reported in subjects with and without PEMCS, which were interactive with adolescent exposure (i.e., current smokers versus nonsmokers) ${ }^{194}$. PEMCS alone was found to increase FA in right and left frontal regions and the genu of the CC. Adolescent smoking alone, in absence of PEMCS, was associated with increased FA in a larger number of frontal regions, the genu and splenium of the CC, the left inferior longitudinal fasciculus, and the anterior limb of right internal capsule (IC). However, PEMCS combined with adolescent smoking was associated with increased FA in an even larger number of regions relative to the other two exposure groups and included the genu of CC, left frontal WM, right superior longitudinal fasciculus, and the anterior limb of the right IC. Direct comparison of adolescent smokers with no PEMCS to prenatally exposed non-smokers revealed significantly higher FA in anterior limb of right IC in the former group. Significant increase in regional white matter FA, primarily in anterior cortical and subcortical areas, was observed following exposure to smoking during the prenatal period alone, the adolescent period alone, and during both developmental epochs. However, increases in FA were more pronounced in adolescent smokers irrespective of PEMCS. This pattern suggests that WM maturation, while potentially affected by PEMCS, is particularly vulnerable to the disruptive effects of nicotine during adolescent development. The IC contains corticospinal,

corticopontine, corticothalamic and the corticofugal fibers. FA of the posterior limb of the left IC correlated well with reaction time during an auditory attention task performance in smokers. However, FA did not correlate with tests of motor efficacy, hinting at the specificity of nicotine effects on the development of thalamocortical and corticofugal fibers, modulating ascending auditory signals, thereby reducing the efficiency of this circuitry. The corticospinal and corticopontine fibers, on the other hand, appear less vulnerable to the effects of PEMCS.

The effects of prenatal and adolescent exposure to cigarette smoke on auditory and visual attention have also been evaluated using fMRI ${ }^{188}$. Similar to the cohort described above, this study had adolescents with and without PEMCS who were and were not currently smoking. Performance accuracy was found to be impaired in the group with PEMCS compared to controls. Within the PEMCS group, males demonstrated greater reductions in performance accuracy during auditory conditions relative to visual conditions, while exposed females had reduced performance accuracy during both auditory and visual attention testing. Activation of the right superior temporal gyrus on fMRI was found to be significantly greater during auditory testing in all exposure groups relative to subjects with neither prenatal nor adolescent exposure. Activation of bilateral lingual gyri was significantly greater in the group with prenatal exposure alone than with subjects who had neither prenatal nor adolescent exposure. Intact cortical cholinergic transmission is required for normal attentional performance ${ }^{198}$. Enhanced cholinergic neurotransmission improves the selectivity of perceptual processing and improves the efficacy of brain regions supporting higher cortical function, an effect associated with reduced activation of regions mediating higher cortical processing 199 . Therefore, these results suggested to the authors a loss of efficiency in cortical regions supporting auditory attention; visualized as areas with greater fMRI activation. The small sample size of the group undergoing fMRI did not allow for conclusions on gender specific fMRI effects. Greater vulnerability of the neurocircuitry supporting auditory attention in males, and both auditory and visual attention in females, following nicotine exposure during prenatal and adolescent development was evident. The authors hypothesize that these gender specific effects on auditory attention may not stem from the global male-female differences in nicotinic receptor binding sites, but may be attributable to gender differences in the downstream effects of $\mathrm{nAChR}$ activation by nicotine or in the hormonal regulation of these downstream effects. Further studies of sub-regions specifically involved in auditory tasks may demonstrate sex related differences in receptor expression or functioning. 
Hippocampus and parahippocampal areas constitute the medial temporal lobe (MTL). The hippocampus is an essential component of the human memory network. It is integral to the synthesis of learned information as well as information recovery during retrieval, and may be involved in spatial learning abilities ${ }^{200}$. fMRI has been used to evaluate visuospatial memory during abstinence from nicotine in adolescent smokers with and without PEMCS ${ }^{185}$.

Adolescent smokers with PEMCS experienced greater nicotine withdrawal related deficits in immediate and delayed visuo-spatial memory relative to adolescent smokers with no PEMCS. Among adolescent smokers with PEMCS, nicotine withdrawal was associated with increased activation of the left parahippocampal gyrus during early recognition testing, and increased activation of the hippocampus bilaterally during delayed recognition testing of the visuo-spatial stimuli. These findings are clinically consistent with prior preclinical studies suggesting alterations in hippocampal architecture associated with combined prenatal and adolescent exposure to cigarette smoke and concomitant deficits in visuo-spatial memory 201 .

At a molecular level, smoking abstinence appears to increase the sensitized nAChRs and thereby the cholinergic neurotransmission in smokers without PEMCS. The reduced MTL activation observed in abstinent adolescent smokers without PEMCS during delayed recognition testing may result from cholinergically mediated enhancements in encoding, leading to reduced hippocampal and parahippocampal load during recognition testing 185 . Conversely, if adolescent smokers with PEMCS do not upregulate nAChRs while smoking and consequently experience decreased cholinergic neurotransmission during abstinence, then the increased MTL activation observed during delayed recognition testing may result from decreased efficacy of encoding, leading to increased hippocampal and parahippocampal load. Increased MTL activation observed during abstinence in the group with PEMCS during recognition testing may reflect compensatory activation in response to deficient encoding. The combined effects of prenatal and adolescent exposure to nicotine produce pronounced and lasting changes in hippocampal functioning.

To summarize, PEMCS has brain regional and gender specificity, with the female fetus being more affected than male fetus. PEMCS produces long lasting structural brain alterations that may well persist into adolescence and adulthood. The results of these studies serve to highlight the need for public awareness, education and preventive measures to reduce nicotine abuse among pregnant women.

\section{CONCLUSIONS}

In this review we have highlighted the putative and hypothesized underlying neuro-teratogenic mechanisms, and selected findings from the behavioral and brain imaging literature, in infants, children, and young adults exposed prenatally to cocaine, methamphetamine, marijuana, alcohol, and tobacco. We specifically chose not to discuss the issue of prenatal exposure to opiates, as to date there has been only one neuroimaging study of this population ${ }^{202}$, and the literature describing possible teratogenic CNS effects of opiates in the developing child is almost non-existent.

Recent advances in brain imaging have greatly contributed to our understanding of the effects of prenatal drug exposure on the developing human brain. This is a relatively new and exciting area of research that will eventually enable us to relate imaging findings to behavior and gene by environment interactions as determinants of critical long term outcomes of children with prenatal drug exposure including psychopathology and adolescent substance use onset.

The number of brain imaging studies related to prenatal drug exposure varies by drug. We were able to identify 20 studies where the drug exposure of interest was alcohol, 10 with cocaine, 5 with tobacco, 4 with marijuana and 2 with methamphetamine. These trends are interesting in 
that, to some extent they coincide with historical trends in drug use patterns in the U.S. and the availability of imaging techniques. Thus, methamphetamine use by pregnant women is a more recent phenomenon and cocaine use became a societal concern as imaging research was also gaining momentum. However, the fewer number of studies of tobacco and marijuana may indicate less interest in these substances among the scientific community.

We say "drug use of interest" because one of the main difficulties in the field of substance use during pregnancy is polysubstance abuse. Most women who use drugs during pregnancy use more than one drug and this is especially true for illegal substances. Women who use cocaine or methamphetamine during pregnancy often also use tobacco, alcohol and marijuana and to a lesser extent, opiates. Among legal prenatal substance users, alcohol and tobacco are often used together. The problem of polydrug use is problematic because very little is known about how drug interactions and combinations affect fetal development and, in order to isolate the effects of a specific drug large sample sizes are needed. With a large sample size there may be enough statistical power and variability among various combinations of drugs to be able to covary or adjust the effects of the drug of interest for the effects of other drugs. However, the complexity and expense of brain imaging studies usually precludes samples that have the statistical power to adjust for covariates. For example, Rivkin ${ }^{35}$ found an initial effect for prenatal cocaine exposure on brain volume but the cocaine effect was no longer statistically significant when other substances were controlled. Therefore, we cannot determine if the "true" effect in this study is a polydrug effect or if unique cocaine effects would be observed with a larger sample size.

In addition, confounding may also arise from factors other than polysubstance abuse, including birth factors such as prematurity and head circumference, and adverse environmental factors such as poverty and poor parenting. Some studies control for confounding variables by study design, such as only selecting subjects exposed to the drug of interest which is feasible with, for example alcohol 160 or cigarette use ${ }^{194}$, or matching subjects for factors such as gender ${ }^{140}$. Factors such as poverty are more problematic for studies of cocaine and methamphetamine, whereas alcohol, tobacco and marijuana can be studied in impoverished and non-impoverished populations. In addition, since most of these studies are cross sectional rather than longitudinal, information on the past history of the children may be sparse or based on recall and subject bias. Documentation of drug use during pregnancy is typically based on self report without verification by toxicological analysis, and subjects may not reveal their true drug use, especially in the case of illegal drugs. Thus, there can be undetected drug users in the comparison group and information on use of other drugs or quantity and frequency of drug use may be suspect. Few of the above studies examined dose response relationships between drug use during pregnancy and imaging results, although the two studies of dose response relationships between prenatal cocaine exposure and neuroimaging were longitudinal studies that included toxicological verification 32,34 .

The sample size of the studies (total of exposed and comparison groups) also varies by drug of interest. Studies examining cocaine exposure have sample sizes ranging from 22-60, methamphetamine 26 and 28, and the marijuana studies range from 11-31. Among the alcohol studies, there is one cohort of $90^{152}$ with the rest of the studies ranging from samples of $2^{162}-45^{153}$. The prenatal tobacco exposure studies include samples of $181^{194} 300^{190}$ and $314^{98}$. By contrast, most studies of the behavioral consequences of prenatal drug exposure are conducted on larger samples. A recent review of the prenatal cocaine exposure literature indicated that more than half of the long term follow-up studies included samples of at least 300 with a maximum of $1,000^{203}$. Therefore, we probably have more confidence in the behavioral findings than in the neuroimaging findings at this time point. Advances in technology including both the software and hardware available on newer MR imaging platforms, as well as the software and data processing pipelines evolving for the rapid and 
unbiased analysis of MR-derived data hold promise for the near future. There are parallel efforts underway to make large normative developmental MR data sets available for the entire brain imaging community, which will be an invaluable resource for researchers in the field.

Interpretation of imaging findings may also be clouded by the ages of the children in the samples. Normal developmental changes in brain maturation could be confused with effects of prenatal drug exposure when children are studied in a cross-sectional manner across a wide age range, especially when the age ranges span periods of major changes in brain development such as early childhood and adolescence. Among the alcohol studies, for example, the ages of the children ranged from $8-22^{145}, 18-37^{152}$ and 3-13 years ${ }^{161}$. Among the tobacco studies the children were 12-18 years. This means that some of the children in these cohorts will be using substances themselves. Thus, the effects of prenatal drug exposure on the brain development may be confounded with effects of current substance abuse.

In addition to these methodological issues, it is important to bear in mind that imaging findings do not tell us about causal mechanisms. They tell us about associations between a condition and brain involvement, but do not help distinguish between cause, effect, or epiphenomena (for a review of this issue, see: Peterson $\mathrm{BS}^{100}$ ). For example, from the studies of prenatal cocaine and methamphetamine exposure, we might speculate that the findings identified in fMRI $^{43}$ MRS $^{85}$, DTI ${ }^{37}$ and cerebral blood flow ${ }^{41}$ studies could well represent either direct effects or involvement of compensatory mechanisms related to other (as yet unknown) areas of the brain. Nor do we know the developmental course of these findings; whether these alterations were present at birth, how the early brain changes from prenatal exposure might impact normative processes of brain development and maturation, and how the postnatal environment may be involved in shaping brain architecture, structure and function. To date, there are no repeated measures studies of children with prenatal drug exposure that would enable us to know whether neuroimaging findings persist over time or if other findings appear with age. Conducting such studies beginning in infancy would help us understand how prenatal drug exposure affects processes of brain development.

It is also noteworthy that we do not know how findings from different imaging procedures relate to each other in this literature and we know little about how imaging findings relate to child behavior and neuro-cognitive function. Future studies will be able to study changes in brain function, structure and connectivity in the same children and determine how these changes relate to the child's behavior in the "real world."

Clearly, we are at the early stages of using brain imaging to help elucidate the effect of prenatal drug exposure. However, there are some interesting findings and trends. It is worthwhile pointing out that this body of work represents a "proof of principle" that this kind of work can be conducted even in very young children. Imaging techniques lend themselves to interrogate the brain in ways that make sense in relation to prenatal drug exposure such as measuring the volume of dopamine rich subcortical regions or designing fMRI tasks that capture brain activity related to the kind of behavioral and neurocognitive deficits that have been described in populations of drug exposed children.

Some findings may be drug specific whereas others may appear across more than one drug class which could mean that there may be some common brain mechanism affected by prenatal exposure to any drug in addition to the specific effects of an individual drug. Both cocaine and methamphetamine were related to smaller volumes in subcortical regions including the dopamine rich putamen. There were effects on increased brain metabolism related to cocaine, methamphetamine, and alcohol. Effects on volumetric MRI, fMRI and DTI were found for cocaine, methamphetamine, alcohol and tobacco suggesting that prenatal drug exposure has long lasting and widespread effects on brain. This is important in light of known mechanisms 
of brain recovery and plasticity following insult and suggests that some prenatal exposure effects are permanent. At the same time, we also saw evidence of potential compensatory mechanisms related to cocaine, methamphetamine, marijuana and tobacco from fMRI and MRS studies, perhaps suggesting mechanisms of neural plasticity and brain recovery. Thus, neuroimaging in children with prenatal drug exposure may be an opportunity to study mechanisms of brain adaptation in addition to deficits. The alcohol literature offers additional insight into this approach showing involvement of specific brain regions with sparing of other areas, demonstrating that not all brain regions may be equally vulnerable to its detrimental effects. Tobacco also appears to have brain regional and gender specificity, with the female fetus being more affected than male fetus. The study of drug by gender interactions could indicate specific biological processes that are affected.

As reviewed above, we have made significant advances using neuroimaging to study the effects of prenatal drug exposure on the brain, but we are just now starting to harness the power of these methods to better understand the problem.

\section{References}

1. Lewis, M.; B, M. Mothers, babies, and cocaine: The role of toxins in development. Hillsdale,NJ: Erlbaum; 1995.

2. Lester BM, LaGasse LL, Seifer R. Cocaine exposure and children: the meaning of subtle effects. Science Oct 23;1998 282(5389):633-634. [PubMed: 9841414]

3. Levitt P, Harvey JA, Friedman E, Simansky K, Murphy EH. New evidence for neurotransmitter influences on brain development. Trends Neurosci Jun;1997 20(6):269-274. [PubMed: 9185309]

4. Mayes LC. Developing brain and in utero cocaine exposure: effects on neural ontogeny. Dev Psychopathol Fall;1999 11(4):685-714. [PubMed: 10624721]

5. Malanga CJ 3rd, Kosofsky BE. Mechanisms of action of drugs of abuse on the developing fetal brain. Clin Perinatol Mar;1999 26(1):17-37. v-vi. [PubMed: 10214541]

6. Meier E, H L, Schousboe A. Neurotransmitters as developmental signals. Neurochemistry international 1991;19(12):1-15.

7. Harvey JA. Cocaine effects on the developing brain: current status. Neurosci Biobehav Rev Jan;2004 27(8):751-764. [PubMed: 15019425]

8. Gressens P, Kosofsky BE, Evrard P. Cocaine-induced disturbances of corticogenesis in the developing murine brain. Neurosci Lett Jun 8;1992 140(1):113-116. [PubMed: 1407688]

9. Kosofsky BE, Wilkins AS, Gressens P, Evrard P. Transplacental cocaine exposure: a mouse model demonstrating neuroanatomic and behavioral abnormalities. J Child Neurol Jul;1994 9(3):234-241. [PubMed: 7930401]

10. Lidow MS, Song ZM. Primates exposed to cocaine in utero display reduced density and number of cerebral cortical neurons. J Comp Neurol Jul 2;2001 435(3):263-275. [PubMed: 11406810]

11. Harvey JA, Romano AG, Gabriel M, et al. Effects of prenatal exposure to cocaine on the developing brain: anatomical, chemical, physiological and behavioral consequences. Neurotox Res Jan;2001 3 (1):117-143. [PubMed: 15111265]

12. Crandall JE, Hackett HE, Tobet SA, Kosofsky BE, Bhide PG. Cocaine exposure decreases GABA neuron migration from the ganglionic eminence to the cerebral cortex in embryonic mice. Cereb Cortex Jun;2004 14(6):665-675. [PubMed: 15054047]

13. Guerriero RM, Rajadhyaksha A, Crozatier C, Giros B, Nosten-Bertrand M, Kosofsky BE. Augmented constitutive CREB expression in the nucleus accumbens and striatum may contribute to the altered behavioral response to cocaine of adult mice exposed to cocaine in utero. Dev Neurosci Mar-Aug; 2005 27(24):235-248. [PubMed: 16046859]

14. Steiner H, Gerfen CR. Dynorphin regulates D1 dopamine receptor-mediated responses in the striatum: relative contributions of pre- and postsynaptic mechanisms in dorsal and ventral striatum demonstrated by altered immediate-early gene induction. J Comp Neurol Dec 23;1996 376(4):530_ 541. [PubMed: 8978468] 
15. Bhat RV, Baraban JM. Activation of transcription factor genes in striatum by cocaine: role of both serotonin and dopamine systems. J Pharmacol Exp Ther Oct;1993 267(1):496-505. [PubMed: 8229780]

16. Novikova SI, He F, Bai J, Badan I, Lidow IA, Lidow MS. Cocaine-induced changes in the expression of apoptosis-related genes in the fetal mouse cerebral wall. Neurotoxicol Teratol Jan-Feb;2005 27 (1):3-14. [PubMed: 15681117]

17. Jensen A, Hohmann M, Kunzel W. Redistribution of fetal circulation during repeated asphyxia in sheep: effects on skin blood flow, transcutaneous PO2, and plasma catecholamines. J Dev Physiol Feb;1987 9(1):41-55. [PubMed: 3559064]

18. Lipton JW, Vu TQ, Ling Z, Gyawali S, Mayer JR, Carvey PM. Prenatal cocaine exposure induces an attenuation of uterine blood flow in the rat. Neurotoxicol Teratol Mar-Apr;2002 24(2):143-148. [PubMed: 11943502]

19. Bassett JM, Hanson C. Catecholamines inhibit growth in fetal sheep in the absence of hypoxemia. Am J Physiol Jun;1998 274(6 Pt 2):R1536-1545. [PubMed: 9608006]

20. Woods JR Jr, Plessinger MA, Clark KE. Effect of cocaine on uterine blood flow and fetal oxygenation. Jama Feb 20;1987 257(7):957-961. [PubMed: 3806879]

21. Koegler SM, Seidler FJ, Spencer JR, Slotkin TA. Ischemia contributes to adverse effects of cocaine on brain development: suppression of ornithine decarboxylase activity in neonatal rat. Brain Res Bull Dec;1991 27(6):829-834. [PubMed: 1786562]

22. Wilkins AS, Marota JJ, Tabit E, Kosofsky BE. Transplacental cocaine exposure. 3: Mechanisms underlying altered brain development. Neurotoxicol Teratol May-Jun;1998 20(3):239-249. [PubMed: 9638681]

23. Lester B, Padbury JF. The Third Pathophysiology of Prenatal Cocaine Exposure. Developmental Neuroscience. in press

24. Shankaran S, Lester BM, Das A, et al. Impact of maternal substance use during pregnancy on childhood outcome. Semin Fetal Neonatal Med Apr;2007 12(2):143-150. [PubMed: 17317350]

25. Frank DA, Augustyn M, Knight WG, Pell T, Zuckerman B. Growth, development, and behavior in early childhood following prenatal cocaine exposure: a systematic review. Jama Mar 28;2001 285 (12):1613-1625. [PubMed: 11268270]

26. Heier LA, Carpanzano CR, Mast J, Brill PW, Winchester P, Deck MD. Maternal cocaine abuse: the spectrum of radiologic abnormalities in the neonatal CNS. AJNR Am J Neuroradiol Sep-Oct;1991 12(5):951-956. [PubMed: 1950928]

27. Gomez-Anson B, Ramsey RG. Pachygyria in a neonate with prenatal cocaine exposure: MR features. J Comput Assist Tomogr Jul-Aug;1994 18(4):637-639. [PubMed: 8040452]

28. Gieron-Korthals MA, Helal A, Martinez CR. Expanding spectrum of cocaine induced central nervous system malformations. Brain Dev May-Jun;1994 16(3):253-256. [PubMed: 7943615]

29. Dixon SD, Bejar R. Echoencephalographic findings in neonates associated with maternal cocaine and methamphetamine use: incidence and clinical correlates. J Pediatr Nov;1989 115(5 Pt 1):770-778. [PubMed: 2681639]

30. Kliegman RM, Madura D, Kiwi R, Eisenberg I, Yamashita T. Relation of maternal cocaine use to the risks of prematurity and low birth weight. J Pediatr May;1994 124(5 Pt 1):751-756. [PubMed: 8176566]

31. Cohen HL, Sloves JH, Laungani S, Glass L, DeMarinis P. Neurosonographic findings in full-term infants born to maternal cocaine abusers: visualization of subependymal and periventricular cysts. $\mathrm{J}$ Clin Ultrasound Jun;1994 22(5):327-333. [PubMed: 8046042]

32. Dow-Edwards DL, Benveniste H, Behnke M, et al. Neuroimaging of prenatal drug exposure. Neurotoxicol Teratol May-Jun;2006 28(3):386-402. [PubMed: 16832875]

33. Avants BB, Hurt H, Giannetta JM, et al. Effects of heavy in utero cocaine exposure on adolescent caudate morphology. Pediatr Neurol Oct;2007 37(4):275-279. [PubMed: 17903672]

34. Neyzi, N.; Quinn, BT.; Kekatpur, M., et al. Segmentation of Brain Structures in a Pediatric Population with Prenatal Cocaine Exposure. Paper presented at: Society for Neuroscience Conference; San Diego. 2007. 
35. Rivkin MJ, Davis PE, Lemaster JL, et al. Volumetric MRI study of brain in children with intrauterine exposure to cocaine, alcohol, tobacco, and marijuana. Pediatrics Apr;2008 121(4):741-750. [PubMed: 18381539]

36. Gabriel M, Taylor C. Prenatal exposure to cocaine impairs neuronal coding of attention and discriminative learning. Ann N Y Acad Sci Jun 21;1998 846:194-212. [PubMed: 9668408]

37. Warner TD, Behnke M, Eyler FD, et al. Diffusion tensor imaging of frontal white matter and executive functioning in cocaine-exposed children. Pediatrics Nov;2006 118(5):2014-2024. [PubMed: 17079574]

38. Smith LM, Chang L, Yonekura ML, et al. Brain proton magnetic resonance spectroscopy and imaging in children exposed to cocaine in utero. Pediatrics Feb;2001 107(2):227-231. [PubMed: 11158451]

39. Smith LM, Qureshi N, Renslo R, Sinow RM. Prenatal cocaine exposure and cranial sonographic findings in preterm infants. J Clin Ultrasound Feb;2001 29(2):72-77. [PubMed: 11425091]

40. Volpe JJ. Effect of cocaine use on the fetus. N Engl J Med Aug 6;1992 327(6):399-407. [PubMed: 1625714]

41. Rao H, Wang J, Giannetta J, et al. Altered resting cerebral blood flow in adolescents with in utero cocaine exposure revealed by perfusion functional MRI. Pediatrics Nov;2007 120(5):e1245-1254. [PubMed: 17974718]

42. Hurt H, Giannetta JM, Korczykowski M, et al. Functional magnetic resonance imaging and working memory in adolescents with gestational cocaine exposure. J Pediatr Mar;2008 152(3):371-377. [PubMed: 18280843]

43. Sheinkopf SJ, Lester BM, Sanes JN, Eliassen JC, Hutchison E, Seifer R, LaGasse L, Durston S, Casey BJ. Functional MRI and Response Inhibition in Children Exposed to Cocaine In Utero: Preliminary Findings. Developmental Neuroscience. in press

44. Greenblatt, JC.; G, J. Methamphetamine abuse in the United States. Rockville, MD: U.S. Department of Health and Human Services, Substance Abuse and Mental Health Services Administration (SAMHSA), Office of Applied Studies; [5/23/08]. 1996 http://www.oas.samhsa.gov/NHSDA/Treatan/treana13.htm

45. Johnston, LD.; OM, P.; Bahman, JG.; Schulenberg, JE. Monitoring the future national survey results on drug use, 1975-2004. Vol. I: secondary school students. Bethesda M: National Institute on Drug Abuse; 2005a.

46. Johnston, LD.; O, MP.; Bahman, JG.; Schulenberg, JE. Monitoring the future national survey results on drug use, 1975-2004. Vol. II: college students and adults ages 19-45. Bethesda M: National Institute on Drug Abuse; 2005b.

47. Anglin MD, B C, Perrochet B, Stamper E, Dawud-Noursi S. History of the methamphetamine problem. J Psychoactive Drugs 2000;32(2):137-141. [PubMed: 10908000]

48. Ho E, Karimi-Tabesh L, Koren G. Characteristics of pregnant women who use ecstasy (3, 4methylenedioxymethamphetamine). Neurotoxicol Teratol Nov-Dec;2001 23(6):561-567. [PubMed: 11792525]

49. Derauf C, K A, Frank DA, Grandinetti A, Easa D. The prevalence of methamphetamine and other drug use during pregnancy in Hawaii. J Drug Issues 2003;3(4):1001-1016.

50. Arria AM, Derauf C, Lagasse LL, et al. Methamphetamine and other substance use during pregnancy: preliminary estimates from the Infant Development, Environment, and Lifestyle (IDEAL) study. Matern Child Health J May;2006 10(3):293-302. [PubMed: 16395620]

51. Skelton MR, Williams MT, Vorhees CV. Developmental effects of 3,4methylenedioxymethamphetamine: a review. Behav Pharmacol Mar;2008 19(2):91-111. [PubMed: 18332674]

52. McCann UD, Ricaurte GA. Amphetamine neurotoxicity: accomplishments and remaining challenges. Neurosci Biobehav Rev Jan;2004 27(8):821-826. [PubMed: 15019431]

53. Frost DO, Cadet JL. Effects of methamphetamine-induced neurotoxicity on the development of neural circuitry: a hypothesis. Brain Res Brain Res Rev Dec;2000 34(3):103-118. [PubMed: 11113502]

54. Quinton MS, Yamamoto BK. Causes and consequences of methamphetamine and MDMA toxicity. Aaps J 2006;8(2):E337-347. [PubMed: 16796384]

55. Weissman AD, Caldecott-Hazard S. Developmental neurotoxicity to methamphetamines. Clin Exp Pharmacol Physiol May;1995 22(5):372-374. [PubMed: 7554435] 
56. Jeng W, Wong AW, Ting AKR, Wells PG. Methamphetamine-enhanced embryonic oxidative DNA damage and neurodevelopmental deficits. Free Radic Biol Med Aug 1;2005 39(3):317-326. [PubMed: 15993330]

57. Robinson TE, Kolb B. Persistent structural modifications in nucleus accumbens and prefrontal cortex neurons produced by previous experience with amphetamine. J Neurosci Nov 1;1997 17(21):84918497. [PubMed: 9334421]

58. Sekine Y, Minabe Y, Ouchi Y, et al. Association of dopamine transporter loss in the orbitofrontal and dorsolateral prefrontal cortices with methamphetamine-related psychiatric symptoms. Am J Psychiatry Sep;2003 160(9):1699-1701. [PubMed: 12944350]

59. Paulus MP, Hozack NE, Zauscher BE, et al. Behavioral and functional neuroimaging evidence for prefrontal dysfunction in methamphetamine-dependent subjects. Neuropsychopharmacology Jan; 2002 26(1):53-63. [PubMed: 11751032]

60. Volkow ND, Chang L, Wang GJ, et al. Association of dopamine transporter reduction with psychomotor impairment in methamphetamine abusers. Am J Psychiatry Mar;2001 158(3):377-382. [PubMed: 11229977]

61. Thompson PM, Hayashi KM, Simon SL, et al. Structural abnormalities in the brains of human subjects who use methamphetamine. J Neurosci Jun 30;2004 24(26):6028-6036. [PubMed: 15229250]

62. Iwazaki T, McGregor IS, Matsumoto I. Protein expression profile in the amygdala of rats with methamphetamine-induced behavioral sensitization. Neurosci Lett Apr 18;2008 435(2):113-119. [PubMed: 18346852]

63. Stanwood GD, Levitt P. Drug exposure early in life: functional repercussions of changing neuropharmacology during sensitive periods of brain development. Curr Opin Pharmacol Feb;2004 4(1):65-71. [PubMed: 15018841]

64. Lewis BA, Singer LT, Short EJ, et al. Four-year language outcomes of children exposed to cocaine in utero. Neurotoxicol Teratol Sep-Oct;2004 26(5):617-627. [PubMed: 15315811]

65. Seifer R, LaGasse LL, Lester B, et al. Attachment status in children prenatally exposed to cocaine and other substances. Child Dev May-Jun;2004 75(3):850-868. [PubMed: 15144490]

66. Bandstra ES, Morrow CE, Anthony JC, Accornero VH, Fried PA. Longitudinal investigation of task persistence and sustained attention in children with prenatal cocaine exposure. Neurotoxicol Teratol Nov-Dec;2001 23(6):545-559. [PubMed: 11792524]

67. Mundy P. Annotation: the neural basis of social impairments in autism: the role of the dorsal medialfrontal cortex and anterior cingulate system. J Child Psychol Psychiatry Sep;2003 44(6):793-809. [PubMed: 12959489]

68. Burchfield DJ, Lucas VW, Abrams RM, Miller RL, DeVane CL. Disposition and pharmacodynamics of methamphetamine in pregnant sheep. Jama Apr 17;1991 265(15):1968-1973. [PubMed: 2008026]

69. Stek AM, Fisher BK, Baker RS, Lang U, Tseng CY, Clark KE. Maternal and fetal cardiovascular responses to methamphetamine in the pregnant sheep. Am J Obstet Gynecol Oct;1993 169(4):888897. [PubMed: 8238145]

70. Stek AM, Baker RS, Fisher BK, Lang U, Clark KE. Fetal responses to maternal and fetal methamphetamine administration in sheep. Am J Obstet Gynecol Nov;1995 173(5):1592-1598. [PubMed: 7503206]

71. Vicentic A, Jones DC. The CART (cocaine- and amphetamine-regulated transcript) system in appetite and drug addiction. J Pharmacol Exp Ther Feb;2007 320(2):499-506. [PubMed: 16840648]

72. Guerrini I, Thomson AD, Gurling HD. The importance of alcohol misuse, malnutrition and genetic susceptibility on brain growth and plasticity. Neurosci Biobehav Rev 2007;31(2):212-220. [PubMed: 16908066]

73. Sizonenko SV, Borradori-Tolsa C, Bauthay DM, Lodygensky G, Lazeyras F, Huppi P. Impact of intrauterine growth restriction and glucocorticoids on brain development: insights using advanced magnetic resonance imaging. Mol Cell Endocrinol Jul 25;2006 254(255):163-171. [PubMed: 16769173]

74. Eriksson M, Larsson G, Winbladh B, Zetterstrom R. The influence of amphetamine addiction on pregnancy and the newborn infant. Acta Paediatr Scand Jan;1978 67(1):95-99. [PubMed: 626072] 
75. Billing L, Eriksson M, Larsson G, Zetterstrom R. Amphetamine addiction and pregnancy. III. One year follow-up of the children. Psychosocial and pediatric aspects. Acta Paediatr Scand Sep;1980 69 (5):675-680. [PubMed: 7234389]

76. Eriksson M, Larsson G, Zetterstrom R. Amphetamine addiction and pregnancy. II. Pregnancy, delivery and the neonatal period. Socio-medical aspects. Acta Obstet Gynecol Scand 1981;60(3): 253-259. [PubMed: 7270093]

77. Eriksson M, Billing L, Steneroth G, Zetterstrom R. Pre-school children of amphetamine-addicted mothers. II. Environment and supportive social welfare. Acta Paediatr Scand Mar;1985 74(2):185190. [PubMed: 3993363]

78. Eriksson M, Billing L, Steneroth G, Zetterstrom R. Health and development of 8-year-old children whose mothers abused amphetamine during pregnancy. Acta Paediatr Scand Nov;1989 78(6):944949. [PubMed: 2603723]

79. Eriksson M, Jonsson B, Steneroth G, Zetterstrom R. Cross-sectional growth of children whose mothers abused amphetamines during pregnancy. Acta Paediatr Jun;1994 83(6):612-617. [PubMed: 7919758]

80. Eriksson M, Zetterstrom R. Amphetamine addiction during pregnancy: 10-year follow-up. Acta Paediatr Suppl Nov;1994 404:27-31. [PubMed: 7531039]

81. Cernerud L, Eriksson M, Jonsson B, Steneroth G, Zetterstrom R. Amphetamine addiction during pregnancy: 14-year follow-up of growth and school performance. Acta Paediatr Feb;1996 85(2):204208. [PubMed: 8640051]

82. Eriksson M, Jonsson B, Steneroth G, Zetterstrom R. Amphetamine abuse during pregnancy: environmental factors and outcome after 14-15 years. Scand J Public Health Jun;2000 28(2):154157. [PubMed: 10954143]

83. Smith LM, Lagasse LL, Derauf C, et al. Prenatal methamphetamine use and neonatal neurobehavioral outcome. Neurotoxicol Teratol Jan-Feb;2008 30(1):20-28. [PubMed: 18031987]

84. Smith LM, LaGasse LL, Derauf C, et al. The infant development, environment, and lifestyle study: effects of prenatal methamphetamine exposure, polydrug exposure, and poverty on intrauterine growth. Pediatrics Sep;2006 118(3):1149-1156. [PubMed: 16951010]

85. Smith LM, Chang L, Yonekura ML, Grob C, Osborn D, Ernst T. Brain proton magnetic resonance spectroscopy in children exposed to methamphetamine in utero. Neurology Jul 24;2001 57(2):255260. [PubMed: 11468309]

86. Kreis R, Ernst T, Ross BD. Development of the human brain: in vivo quantification of metabolite and water content with proton magnetic resonance spectroscopy. Magn Reson Med Oct;1993 30(4): 424-437. [PubMed: 8255190]

87. Toft PB, Christiansen P, Pryds O, Lou HC, Henriksen O. T1, T2, and concentrations of brain metabolites in neonates and adolescents estimated with H-1 MR spectroscopy. J Magn Reson Imaging Jan-Feb;1994 4(1):1-5. [PubMed: 7908545]

88. Toft PB, Leth H, Lou HC, Pryds O, Henriksen O. Metabolite concentrations in the developing brain estimated with proton MR spectroscopy. J Magn Reson Imaging Sep-Oct;1994 4(5):674-680. [PubMed: 7981512]

89. Kreis R, Hofmann L, Kuhlmann B, Boesch C, Bossi E, Huppi PS. Brain metabolite composition during early human brain development as measured by quantitative in vivo $1 \mathrm{H}$ magnetic resonance spectroscopy. Magn Reson Med Dec;2002 48(6):949-958. [PubMed: 12465103]

90. Filippi CG, Ulug AM, Deck MD, Zimmerman RD, Heier LA. Developmental delay in children: assessment with proton MR spectroscopy. AJNR Am J Neuroradiol May;2002 23(5):882-888. [PubMed: 12006297]

91. Sokol DK, Dunn DW, Edwards-Brown M, Feinberg J. Hydrogen proton magnetic resonance spectroscopy in autism: preliminary evidence of elevated choline/creatine ratio. J Child Neurol Apr; 2002 17(4):245-249. [PubMed: 12088077]

92. Murphy DG, Critchley HD, Schmitz N, et al. Asperger syndrome: a proton magnetic resonance spectroscopy study of brain. Arch Gen Psychiatry Oct;2002 59(10):885-891. [PubMed: 12365875]

93. MacMaster FP, Carrey N, Sparkes S, Kusumakar V. Proton spectroscopy in medication-free pediatric attention-deficit/hyperactivity disorder. Biol Psychiatry Jan 15;2003 53(2):184-187. [PubMed: 12547476] 
94. Courvoisie H, Hooper SR, Fine C, Kwock L, Castillo M. Neurometabolic functioning and neuropsychological correlates in children with ADHD-H: preliminary findings. J Neuropsychiatry Clin Neurosci Winter;2004 16(1):63-69. [PubMed: 14990761]

95. Ross BD, Ernst T, Kreis R, et al. 1H MRS in acute traumatic brain injury. J Magn Reson Imaging Jul-Aug;1998 8(4):829-840. [PubMed: 9702884]

96. Ashwal S, Holshouser B, Tong K, et al. Proton MR spectroscopy detected glutamate/glutamine is increased in children with traumatic brain injury. J Neurotrauma Nov;2004 21(11):1539-1552. [PubMed: 15684647]

97. Chang L, Smith LM, LoPresti C, et al. Smaller subcortical volumes and cognitive deficits in children with prenatal methamphetamine exposure. Psychiatry Res Dec 15;2004 132(2):95-106. [PubMed: 15598544]

98. Toro R, Leonard G, Lerner JV, et al. Prenatal exposure to maternal cigarette smoking and the adolescent cerebral cortex. Neuropsychopharmacology Apr;2008 33(5):1019-1027. [PubMed: 17609681]

99. Spadoni AD, McGee CL, Fryer SL, Riley EP. Neuroimaging and fetal alcohol spectrum disorders. Neurosci Biobehav Rev 2007;31(2):239-245. [PubMed: 17097730]

100. Peterson BS. Conceptual, methodological, and statistical challenges in brain imaging studies of developmentally based psychopathologies. Dev Psychopathol Summer;2003 15(3):811-832. [PubMed: 14582941]

101. Teicher MH, Anderson CM, Polcari A, Glod CA, Maas LC, Renshaw PF. Functional deficits in basal ganglia of children with attention-deficit/hyperactivity disorder shown with functional magnetic resonance imaging relaxometry. Nat Med Apr;2000 6(4):470-473. [PubMed: 10742158]

102. Castellanos FX, Giedd JN, Marsh WL, et al. Quantitative brain magnetic resonance imaging in attention-deficit hyperactivity disorder. Arch Gen Psychiatry Jul;1996 53(7):607-616. [PubMed: 8660127]

103. Castellanos FX, Sharp WS, Gottesman RF, Greenstein DK, Giedd JN, Rapoport JL. Anatomic brain abnormalities in monozygotic twins discordant for attention deficit hyperactivity disorder. Am J Psychiatry Sep;2003 160(9):1693-1696. [PubMed: 12944348]

104. Drug use among women delivering live births, 1992 Vol NIH Publication Number 96-3819: NIDA. Rockville, MD: National Pregnancy and Health Survey; 1996.

105. Fried PA, Smith AM. A literature review of the consequences of prenatal marihuana exposure. An emerging theme of a deficiency in aspects of executive function. Neurotoxicol Teratol Jan-Feb; 2001 23(1):1-11. [PubMed: 11274871]

106. Ameri A. The effects of cannabinoids on the brain. Prog Neurobiol Jul;1999 58(4):315-348. [PubMed: 10368032]

107. Tanda G, Goldberg SR. Cannabinoids: reward, dependence, and underlying neurochemical mechanisms--a review of recent preclinical data. Psychopharmacology (Berl) Sep;2003 169(2): 115-134. [PubMed: 12827346]

108. Mackie K, Stella N. Cannabinoid receptors and endocannabinoids: evidence for new players. Aaps J 2006;8(2):E298-306. [PubMed: 16796380]

109. Harkany T, Guzman M, Galve-Roperh I, Berghuis P, Devi LA, Mackie K. The emerging functions of endocannabinoid signaling during CNS development. Trends Pharmacol Sci Feb;2007 28(2):8392. [PubMed: 17222464]

110. Glass M, Dragunow M, Faull RL. Cannabinoid receptors in the human brain: a detailed anatomical and quantitative autoradiographic study in the fetal, neonatal and adult human brain. Neuroscience Mar;1997 77(2):299-318. [PubMed: 9472392]

111. Bernard C, Milh M, Morozov YM, Ben-Ari Y, Freund TF, Gozlan H. Altering cannabinoid signaling during development disrupts neuronal activity. Proc Natl Acad Sci U S A Jun 28;2005 102(26): 9388-9393. [PubMed: 15964987]

112. Lester BM, Dreher M. Effects of marijuana use during pregnancy on newborn cry. Child Dev Aug; 1989 60(4):765-771. [PubMed: 2758874]

113. Scher MS, Richardson GA, Day NL. Effects of prenatal cocaine/crack and other drug exposure on electroencephalographic sleep studies at birth and one year. Pediatrics Jan;2000 105(1 Pt 1):39-48. [PubMed: 10617702] 
114. Goldschmidt L, Richardson GA, Willford J, Day NL. Prenatal Marijuana Exposure and Intelligence Test Performance at Age 6. J Am Acad Child Adolesc Psychiatry. Jan 22;2008

115. Day NL, Richardson GA, Goldschmidt L, et al. Effect of prenatal marijuana exposure on the cognitive development of offspring at age three. Neurotoxicol Teratol Mar-Apr;1994 16(2):169_ 175. [PubMed: 8052191]

116. Fried PA, Watkinson B. 36- and 48-month neurobehavioral follow-up of children prenatally exposed to marijuana, cigarettes, and alcohol. J Dev Behav Pediatr Apr;1990 11(2):49-58. [PubMed: 2324288]

117. Fried PA, Watkinson B, Gray R. Growth from birth to early adolescence in offspring prenatally exposed to cigarettes and marijuana. Neurotoxicol Teratol Sep-Oct;1999 21(5):513-525. [PubMed: 10492386]

118. Fried PA, Watkinson B. Differential effects on facets of attention in adolescents prenatally exposed to cigarettes and marihuana. Neurotoxicol Teratol Sep-Oct;2001 23(5):421-430. [PubMed: 11711244]

119. Richardson GA, Ryan C, Willford J, Day NL, Goldschmidt L. Prenatal alcohol and marijuana exposure: effects on neuropsychological outcomes at 10 years. Neurotoxicol Teratol May-Jun;2002 24(3):309-320. [PubMed: 12009486]

120. Goldschmidt L, Day NL, Richardson GA. Effects of prenatal marijuana exposure on child behavior problems at age 10. Neurotoxicol Teratol May-Jun;2000 22(3):325-336. [PubMed: 10840176]

121. Smith AM, Fried PA, Hogan MJ, Cameron I. Effects of prenatal marijuana on visuospatial working memory: an fMRI study in young adults. Neurotoxicol Teratol Mar-Apr;2006 28(2):286-295. [PubMed: 16473495]

122. Wilson W, Mathew R, Turkington T, Hawk T, Coleman RE, Provenzale J. Brain morphological changes and early marijuana use: a magnetic resonance and positron emission tomography study. J Addict Dis 2000;19(1):1-22. [PubMed: 10772599]

123. Quickfall J, Crockford D. Brain neuroimaging in cannabis use: a review. J Neuropsychiatry Clin Neurosci Summer;2006 18(3):318-332. [PubMed: 16963581]

124. Chang L, Chronicle EP. Functional imaging studies in cannabis users. Neuroscientist Oct;2007 13 (5):422-432. [PubMed: 17901252]

125. Smith AM, Fried PA, Hogan MJ, Cameron I. Effects of prenatal marijuana on response inhibition: an fMRI study of young adults. Neurotoxicol Teratol Jul-Aug;2004 26(4):533-542. [PubMed: 15203175]

126. Jones KL, Smith DW. Recognition of the fetal alcohol syndrome in early infancy. Lancet Nov 3;1973 2(7836):999-1001. [PubMed: 4127281]

127. May PA, Gossage JP. Estimating the prevalence of fetal alcohol syndrome. A summary. Alcohol Res Health 2001;25(3):159-167. [PubMed: 11810953]

128. Bauer-Moffett C, Altman J. The effect of ethanol chronically administered to preweanling rats on cerebellar development: a morphological study. Brain Res Jan 7;1977 119(2):249-268. [PubMed: 830387]

129. Bonthius DJ, West JR. Alcohol-induced neuronal loss in developing rats: increased brain damage with binge exposure. Alcohol Clin Exp Res Feb;1990 14(1):107-118. [PubMed: 1689970]

130. Miller MW, Robertson S. Prenatal exposure to ethanol alters the postnatal development and transformation of radial glia to astrocytes in the cortex. J Comp Neurol 1993;337(2):253-266. [PubMed: 8276999]

131. Gressens P, Lammens M, Picard JJ, Evrard P. Ethanol-induced disturbances of gliogenesis and neuronogenesis in the developing murine brain: an in vitro and in vivo immunohistochemical and ultrastructural study. Alcohol Alcohol 1992;27(3):219-226. [PubMed: 1449557]

132. Olney JW, Ishimaru MJ, Bittigau P, Ikonomidou C. Ethanol-induced apoptotic neurodegeneration in the developing brain. Apoptosis Dec;2000 5(6):515-521. [PubMed: 11303910]

133. Shankar K, Ronis MJ, Badger TM. Effects of pregnancy and nutritional status on alcohol metabolism. Alcohol Res Health 2007;30(1):55-59. [PubMed: 17718402]

134. May PA, Gossage JP, Marais AS, et al. Maternal risk factors for fetal alcohol syndrome and partial fetal alcohol syndrome in South Africa: a third study. Alcohol Clin Exp Res May;2008 32(5):738753. [PubMed: 18336634] 
135. Warren KR, Li TK. Genetic polymorphisms: impact on the risk of fetal alcohol spectrum disorders. Birth Defects Res A Clin Mol Teratol Apr;2005 73(4):195-203. [PubMed: 15786496]

136. Mitchell JJ, Paiva M, Moore DB, Walker DW, Heaton MB. A comparative study of ethanol, hypoglycemia, hypoxia and neurotrophic factor interactions with fetal rat hippocampal neurons: a multi-factor in vitro model developmental ethanol effects. Brain Res Dev Brain Res Feb 10;1998 105(2):241-250.

137. Colton CA, Snell-Callanan J, Chernyshev ON. Ethanol induced changes in superoxide anion and nitric oxide in cultured microglia. Alcohol Clin Exp Res May;1998 22(3):710-716. [PubMed: 9622454]

138. Bearer CF. L1 cell adhesion molecule signal cascades: targets for ethanol developmental neurotoxicity. Neurotoxicology Oct;2001 22(5):625-633. [PubMed: 11770884]

139. Guerri C. Neuroanatomical and neurophysiological mechanisms involved in central nervous system dysfunctions induced by prenatal alcohol exposure. Alcohol Clin Exp Res Apr;1998 22(2):304312. [PubMed: 9581633]

140. Archibald SL, Fennema-Notestine C, Gamst A, Riley EP, Mattson SN, Jernigan TL. Brain dysmorphology in individuals with severe prenatal alcohol exposure. Dev Med Child Neurol Mar; 2001 43(3):148-154. [PubMed: 11263683]

141. Autti-Ramo I, Autti T, Korkman M, Kettunen S, Salonen O, Valanne L. MRI findings in children with school problems who had been exposed prenatally to alcohol. Dev Med Child Neurol Feb; 2002 44(2):98-106. [PubMed: 11848116]

142. Sowell ER, Thompson PM, Mattson SN, et al. Voxel-based morphometric analyses of the brain in children and adolescents prenatally exposed to alcohol. Neuroreport Mar 5;2001 12(3):515-523. [PubMed: 11234756]

143. Sowell ER, Thompson PM, Mattson SN, et al. Regional brain shape abnormalities persist into adolescence after heavy prenatal alcohol exposure. Cereb Cortex Aug;2002 12(8):856-865. [PubMed: 12122034]

144. Sowell ER, Mattson SN, Thompson PM, Jernigan TL, Riley EP, Toga AW. Mapping callosal morphology and cognitive correlates: effects of heavy prenatal alcohol exposure. Neurology Jul 24;2001 57(2):235-244. [PubMed: 11468307]

145. Sowell ER, Thompson PM, Peterson BS, et al. Mapping cortical gray matter asymmetry patterns in adolescents with heavy prenatal alcohol exposure. Neuroimage Dec;2002 17(4):1807-1819. [PubMed: 12498754]

146. Kodituwakku PW, Kalberg W, May PA. The effects of prenatal alcohol exposure on executive functioning. Alcohol Res Health 2001;25(3):192-198. [PubMed: 11810957]

147. Sowell ER, Mattson SN, Kan E, Thompson PM, Riley EP, Toga AW. Abnormal cortical thickness and brain-behavior correlation patterns in individuals with heavy prenatal alcohol exposure. Cereb Cortex Jan;2008 18(1):136-144. [PubMed: 17443018]

148. Narr KL, Bilder RM, Toga AW, et al. Mapping cortical thickness and gray matter concentration in first episode schizophrenia. Cereb Cortex Jun;2005 15(6):708-719. [PubMed: 15371291]

149. Shaw $P$, Greenstein D, Lerch J, et al. Intellectual ability and cortical development in children and adolescents. Nature Mar 30;2006 440(7084):676-679. [PubMed: 16572172]

150. Swayze VW 2nd, Johnson VP, Hanson JW, et al. Magnetic resonance imaging of brain anomalies in fetal alcohol syndrome. Pediatrics Feb;1997 99(2):232-240. [PubMed: 9024452]

151. Riley EP, Mattson SN, Sowell ER, Jernigan TL, Sobel DF, Jones KL. Abnormalities of the corpus callosum in children prenatally exposed to alcohol. Alcohol Clin Exp Res Oct;1995 19(5):11981202. [PubMed: 8561290]

152. Bookstein FL, Sampson PD, Streissguth AP, Connor PD. Geometric morphometrics of corpus callosum and subcortical structures in the fetal-alcohol-affected brain. Teratology Jul;2001 64(1): 4-32. [PubMed: 11410908]

153. Bookstein FL, Streissguth AP, Sampson PD, Connor PD, Barr HM. Corpus callosum shape and neuropsychological deficits in adult males with heavy fetal alcohol exposure. Neuroimage Jan;2002 15(1):233-251. [PubMed: 11771992] 
154. Ma X, Coles CD, Lynch ME, et al. Evaluation of corpus callosum anisotropy in young adults with fetal alcohol syndrome according to diffusion tensor imaging. Alcohol Clin Exp Res Jul;2005 29 (7):1214-1222. [PubMed: 16046877]

155. Wozniak JR, Mueller BA, Chang PN, Muetzel RL, Caros L, Lim KO. Diffusion tensor imaging in children with fetal alcohol spectrum disorders. Alcohol Clin Exp Res Oct;2006 30(10):1799-1806. [PubMed: 17010147]

156. Sowell ER, Johnson A, Kan E, et al. Mapping white matter integrity and neurobehavioral correlates in children with fetal alcohol spectrum disorders. J Neurosci Feb 6;2008 28(6):1313-1319. [PubMed: 18256251]

157. Roebuck TM, Mattson SN, Riley EP. Interhemispheric transfer in children with heavy prenatal alcohol exposure. Alcohol Clin Exp Res Dec;2002 26(12):1863-1871. [PubMed: 12500111]

158. Kim JJ, Thompson RF. Cerebellar circuits and synaptic mechanisms involved in classical eyeblink conditioning. Trends Neurosci Apr;1997 20(4):177-181. [PubMed: 9106359]

159. Sowell ER, Jernigan TL, Mattson SN, Riley EP, Sobel DF, Jones KL. Abnormal development of the cerebellar vermis in children prenatally exposed to alcohol: size reduction in lobules I-V. Alcohol Clin Exp Res Feb;1996 20(1):31-34. [PubMed: 8651458]

160. O'Hare ED, Kan E, Yoshii J, et al. Mapping cerebellar vermal morphology and cognitive correlates in prenatal alcohol exposure. Neuroreport Aug 22;2005 16(12):1285-1290. [PubMed: 16056126]

161. Riikonen R, Salonen I, Partanen K, Verho S. Brain perfusion SPECT and MRI in foetal alcohol syndrome. Dev Med Child Neurol Oct;1999 41(10):652-659. [PubMed: 10587040]

162. Mattson SN, Riley EP, Jernigan TL, et al. A decrease in the size of the basal ganglia following prenatal alcohol exposure: a preliminary report. Neurotoxicol Teratol May-Jun;1994 16(3):283289. [PubMed: 7935262]

163. Mattson SN, Riley EP, Sowell ER, Jernigan TL, Sobel DF, Jones KL. A decrease in the size of the basal ganglia in children with fetal alcohol syndrome. Alcohol Clin Exp Res Sep;1996 20(6):10881093. [PubMed: 8892532]

164. Clark CM, Li D, Conry J, Conry R, Loock C. Structural and functional brain integrity of fetal alcohol syndrome in nonretarded cases. Pediatrics May;2000 105(5):1096-1099. [PubMed: 10790468]

165. Cortese BM, Moore GJ, Bailey BA, Jacobson SW, Delaney-Black V, Hannigan JH. Magnetic resonance and spectroscopic imaging in prenatal alcohol-exposed children: preliminary findings in the caudate nucleus. Neurotoxicol Teratol Sep-Oct;2006 28(5):597-606. [PubMed: 16996247]

166. Ebrahim SH, Floyd RL, Merritt RK 2nd, Decoufle P, Holtzman D. Trends in pregnancy-related smoking rates in the United States, 1987-1996. Jama Jan 19;2000 283(3):361-366. [PubMed: 10647799]

167. Martin JA, Hamilton BE, Ventura SJ, Menacker F, Park MM, Sutton PD. Births: final data for 2001. Natl Vital Stat Rep Dec 18;2002 51(2):1-102. [PubMed: 12596439]

168. Martin JA, Kochanek KD, Strobino DM, Guyer B, MacDorman MF. Annual summary of vital statistics--2003. Pediatrics Mar;2005 115(3):619-634. [PubMed: 15741364]

169. Ernst M, Moolchan ET, Robinson ML. Behavioral and neural consequences of prenatal exposure to nicotine. J Am Acad Child Adolesc Psychiatry Jun;2001 40(6):630-641. [PubMed: 11392340]

170. Slotkin TA, Seidler FJ, Qiao D, et al. Effects of prenatal nicotine exposure on primate brain development and attempted amelioration with supplemental choline or vitamin C: neurotransmitter receptors, cell signaling and cell development biomarkers in fetal brain regions of rhesus monkeys. Neuropsychopharmacology Jan;2005 30(1):129-144. [PubMed: 15316571]

171. Schneider AS, Atluri P, Shen Q, et al. Functional nicotinic acetylcholine receptor expression on stem and progenitor cells of the early embryonic nervous system. Ann N Y Acad Sci Oct;2002 971:135-138. [PubMed: 12438103]

172. Slotkin TA. Cholinergic systems in brain development and disruption by neurotoxicants: nicotine, environmental tobacco smoke, organophosphates. Toxicol Appl Pharmacol Jul 15;2004 198(2): 132-151. [PubMed: 15236950]

173. Muneoka K, Nakatsu T, Fuji J, Ogawa T, Takigawa M. Prenatal administration of nicotine results in dopaminergic alterations in the neocortex. Neurotoxicol Teratol Sep-Oct;1999 21(5):603-609. [PubMed: 10492395] 
174. Muneoka K, Ogawa T, Kamei K, et al. Prenatal nicotine exposure affects the development of the central serotonergic system as well as the dopaminergic system in rat offspring: involvement of route of drug administrations. Brain Res Dev Brain Res Aug 18;1997 102(1):117-126.

175. Richardson SA, Tizabi Y. Hyperactivity in the offspring of nicotine-treated rats: role of the mesolimbic and nigrostriatal dopaminergic pathways. Pharmacol Biochem Behav Feb;1994 47(2): 331-337. [PubMed: 8146225]

176. Xu Z, Seidler FJ, Ali SF, Slikker W Jr, Slotkin TA. Fetal and adolescent nicotine administration: effects on CNS serotonergic systems. Brain Res Sep 28;2001 914(12):166-178. [PubMed: 11578609]

177. Ernst M, Matochik JA, Heishman SJ, et al. Effect of nicotine on brain activation during performance of a working memory task. Proc Natl Acad Sci U S A Apr 10;2001 98(8):4728-4733. [PubMed: 11274349]

178. Shea AK, Steiner M. Cigarette smoking during pregnancy. Nicotine Tob Res Feb;2008 10(2):267278. [PubMed: 18236291]

179. Kallen K. Maternal smoking during pregnancy and infant head circumference at birth. Early Hum Dev Jun;2000 58(3):197-204. [PubMed: 10936439]

180. Shankaran S, Das A, Bauer CR, et al. Association between patterns of maternal substance use and infant birth weight, length, and head circumference. Pediatrics Aug;2004 114(2):e226-234. [PubMed: 15286261]

181. Weissman MM, Warner V, Wickramaratne PJ, Kandel DB. Maternal smoking during pregnancy and psychopathology in offspring followed to adulthood. J Am Acad Child Adolesc Psychiatry Jul; 1999 38(7):892-899. [PubMed: 10405508]

182. Breslau N, Chilcoat HD. Psychiatric sequelae of low birth weight at 11 years of age. Biol Psychiatry Jun 1;2000 47(11):1005-1011. [PubMed: 10838069]

183. Milberger S, Biederman J, Faraone SV, Jones J. Further evidence of an association between maternal smoking during pregnancy and attention deficit hyperactivity disorder: findings from a high-risk sample of siblings. J Clin Child Psychol Oct;1998 27(3):352-358. [PubMed: 9789194]

184. D'Onofrio BM, Van Hulle CA, Waldman ID, et al. Smoking during pregnancy and offspring externalizing problems: an exploration of genetic and environmental confounds. Dev Psychopathol Winter;2008 20(1):139-164. [PubMed: 18211732]

185. Jacobsen LK, Slotkin TA, Westerveld M, Mencl WE, Pugh KR. Visuospatial memory deficits emerging during nicotine withdrawal in adolescents with prenatal exposure to active maternal smoking. Neuropsychopharmacology Jul;2006 31(7):1550-1561. [PubMed: 16341023]

186. Fried PA. Prenatal exposure to marihuana and tobacco during infancy, early and middle childhood: effects and an attempt at synthesis. Arch Toxicol Suppl 1995;17:233-260. [PubMed: 7786162]

187. Obel C, Henriksen TB, Hedegaard M, Secher NJ, Ostergaard J. Smoking during pregnancy and babbling abilities of the 8-month-old infant. Paediatr Perinat Epidemiol Jan;1998 12(1):37-48. [PubMed: 9483616]

188. Jacobsen LK, Slotkin TA, Mencl WE, Frost SJ, Pugh KR. Gender-specific effects of prenatal and adolescent exposure to tobacco smoke on auditory and visual attention. Neuropsychopharmacology Dec;2007 32(12):2453-2464. [PubMed: 17375135]

189. Slikker W Jr, Xu ZA, Levin ED, Slotkin TA. Mode of action: disruption of brain cell replication, second messenger, and neurotransmitter systems during development leading to cognitive dysfunction--developmental neurotoxicity of nicotine. Crit Rev Toxicol Oct-Nov;2005 35(89):703711. [PubMed: 16417037]

190. Paus T, Nawazkhan I, Leonard G, et al. Corpus callosum in adolescent offspring exposed prenatally to maternal cigarette smoking. Neuroimage Apr 1;2008 40(2):435-441. [PubMed: 18221892]

191. Hofer S, Frahm J. Topography of the human corpus callosum revisited--comprehensive fiber tractography using diffusion tensor magnetic resonance imaging. Neuroimage Sep;2006 32(3):989_ 994. [PubMed: 16854598]

192. Herlenius E, Lagercrantz H. Neurotransmitters and neuromodulators during early human development. Early Hum Dev Oct;2001 65(1):21-37. [PubMed: 11520626]

193. Seguin JR. Neurocognitive elements of antisocial behavior: Relevance of an orbitofrontal cortex account. Brain Cogn Jun;2004 55(1):185-197. [PubMed: 15134852] 
194. Jacobsen LK, Picciotto MR, Heath CJ, et al. Prenatal and adolescent exposure to tobacco smoke modulates the development of white matter microstructure. J Neurosci Dec 5;2007 27(49):1349113498. [PubMed: 18057207]

195. Beaulieu C. The basis of anisotropic water diffusion in the nervous system - a technical review. NMR Biomed Nov-Dec;2002 15(78):435-455. [PubMed: 12489094]

196. Barnea-Goraly N, Menon V, Eckert M, et al. White matter development during childhood and adolescence: a cross-sectional diffusion tensor imaging study. Cereb Cortex Dec;2005 15(12): 1848-1854. [PubMed: 15758200]

197. Mabbott DJ, Noseworthy M, Bouffet E, Laughlin S, Rockel C. White matter growth as a mechanism of cognitive development in children. Neuroimage Nov 15;2006 33(3):936-946. [PubMed: 16978884]

198. Sarter M, Hasselmo ME, Bruno JP, Givens B. Unraveling the attentional functions of cortical cholinergic inputs: interactions between signal-driven and cognitive modulation of signal detection. Brain Res Brain Res Rev Feb;2005 48(1):98-111. [PubMed: 15708630]

199. Furey ML, Pietrini P, Haxby JV. Cholinergic enhancement and increased selectivity of perceptual processing during working memory. Science Dec 22;2000 290(5500):2315-2319. [PubMed: 11125148]

200. McClelland JL, Goddard NH. Considerations arising from a complementary learning systems perspective on hippocampus and neocortex. Hippocampus 1996;6(6):654-665. [PubMed: 9034852]

201. Abreu-Villaca Y, Seidler FJ, Slotkin TA. Does prenatal nicotine exposure sensitize the brain to nicotine-induced neurotoxicity in adolescence? Neuropsychopharmacology Aug;2004 29(8):14401450. [PubMed: 15039772]

202. Walhovd KB, Moe V, Slinning K, Due-Tonnessen P, Bjornerud A, Dale AM, van der Kouwe A, Quinn BT, Kosofsky B, Greve D, Fischl B. Volumetric cerebral characteristics of children exposed to opiates and other substances in utero. Neuroimage 2007;36(4):1331-1344. [PubMed: 17513131]

203. Lester BM, Lagasse LL. Children of Addicted Women, in Women, Children and Addiction. Supplement to the Journal of Addictive Diseases. in press 